\title{
FINITE ELEMENT MODELING OF STEEL PLATES UNDER MONOTONIC LOADING
}

\author{
by: \\ Bilal Nasir Shamsaldin \\ BASc, University of Windsor, Ontario, 2016 \\ A major research project \\ presented to Ryerson University \\ in partial fulfillment of the \\ requirements for the degree of \\ Master of Engineering \\ in the Program of \\ Civil Engineering
}

Toronto, Ontario, Canada, 2019

(C) Bilal N. Shamsaldin, 2019 


\section{Author's Declaration}

\section{AUTHOR'S DECLARATION FOR ELECTRONIC SUBMISSION OF AN MRP}

I hereby declare that I am the sole author of this MRP. This is a true copy of the MRP, including any required final revisions.

I authorize Ryerson University to lend this MRP to other institutions or individuals for the purpose of scholarly research

I further authorize Ryerson University to reproduce this MRP by photocopying or by other means, in total or in part, at the request of other institutions or individuals for the purpose of scholarly research. I understand that my MRP may be made electronically available to the public. 


\author{
Abstract \\ FINITE ELEMENT MODELING OF STEEL PLATES UNDER MONOTONIC LOADING \\ Master of Engineering, 2019 \\ Bilal Nasir Shamsaldin \\ Program of Civil Engineering \\ Ryerson University
}

Steel plate fuses can be used as energy dissipating devices in earthquake-resistant structures. After an earthquake, the structure remains essentially elastic and only the deformed fuse require replacement. This report simulates the monotonic response of steel plate specimens. The effects of different inputs such as imperfection, shape and size of the fuse openings, and different meshing types on yield strength, deformation, stress distribution, and displacement are studied by using ANSYS Mechanical APDL. The study found that increasing imperfection increases displacement and decreases yield strength. It was also concluded that as the hole size in the steel plate is increased, the fuse yield strength is slightly increased to a point then is decreased. Double diamond shape showed better response in terms of displacement and stress distribution, this is because of the link shape formed by the two holes. Finer quadrilateral meshing method provide precise simulation results over longer time. 


\section{Acknowledgments}

Special thanks of gratitude to Dr. Saber Moradi for his guidance, support and help in completing this project. Extended gratitude to Ph.D. Candidate Majid Mohammadi Nia for his help with the finite element model. 


\section{Table of Contents}

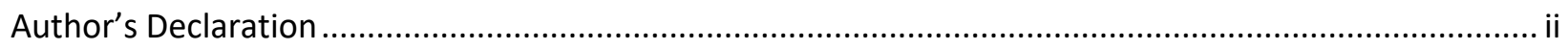

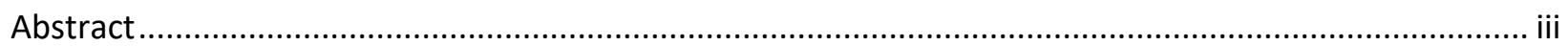

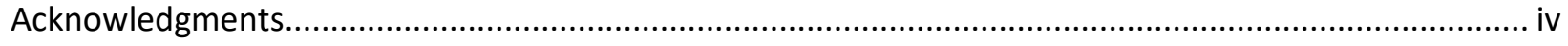

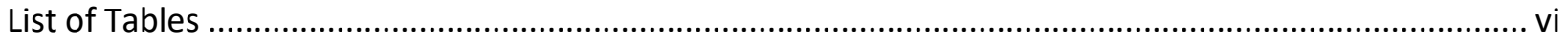

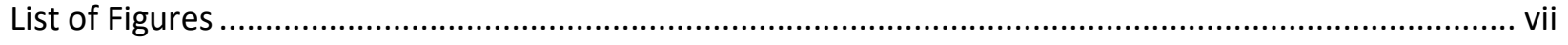

1. Introduction

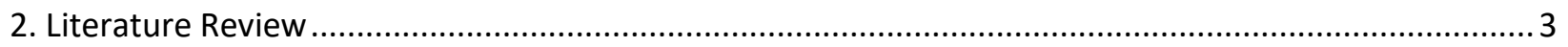

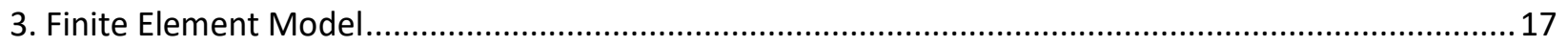

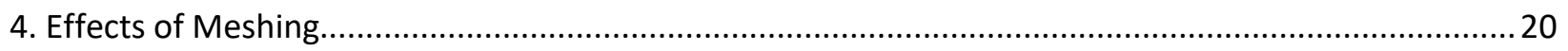

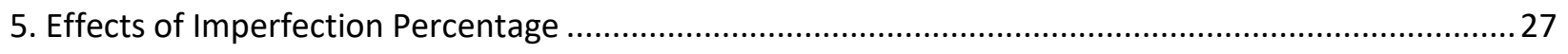

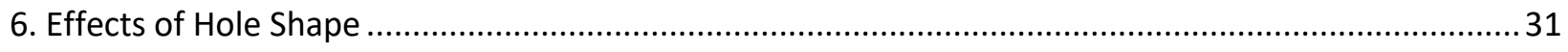

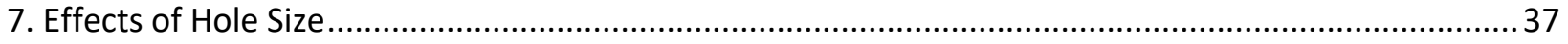

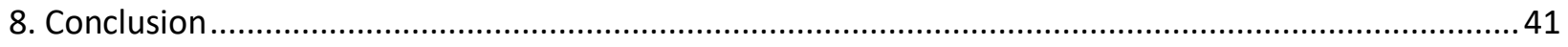

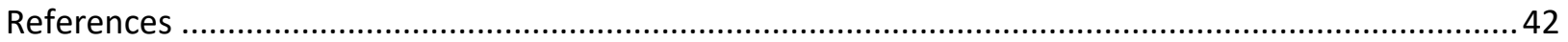




\section{List of Tables}

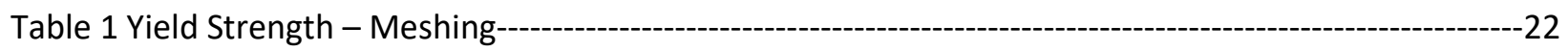

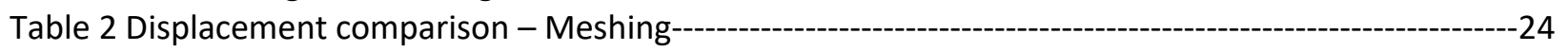

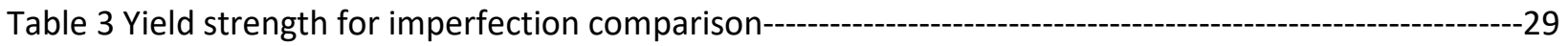




\section{List of Figures}

Figure 1 Fuse with links (Xiang, et al., 2011)---------1

Figure 2 A) Hybrid energy dissipation system B) Semi-active energy dissipation systems C) Passive energy dissipation system (Soong \& Spencer, 2002)--------Figure 3 Hysteretic behaviour of A) Viscous fluid damper B) Viscoelastic solid damper C) Metallic damper and D) friction damper (Symans MD, 2008)-----Figure 4 A) structure without passive energy dissipation B) Structure with passive energy dissipation----7 Figure 5 Steel shear panel dampers used in (Deng, Pan, Sun, Liu, \& Xue, 2014) study.--------------------9 Figure 6 A) Prismatic slit dampers B) Dumbbell shaped strip C) Tapered strip D) Hourglass shaped strip (Lee, Ju, Min, Lho , \& Kim, 2015)----

Figure 7 A) Proposed design by (Foti, Nobile, \& Diaferio, 2013) B) Placement of the aluminum plate----12 Figure 8 Proposed building design by (Kurokawa, Sakamoto, Yamada, Kurino, \& Kunisue, 1998)---------13

Figure 9 Composite plate used in (Madenci \& Guven, 2006) study-----------18

Figure 10 Meshed plate from FEM---

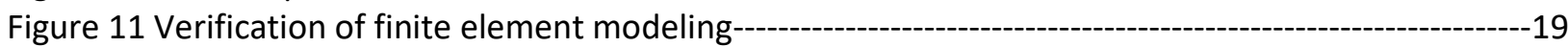

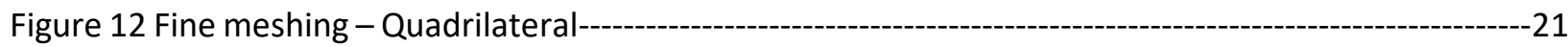

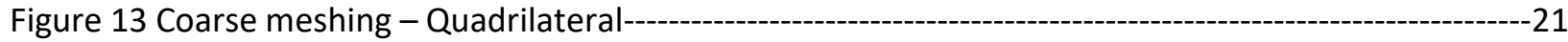

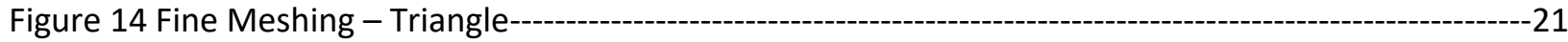

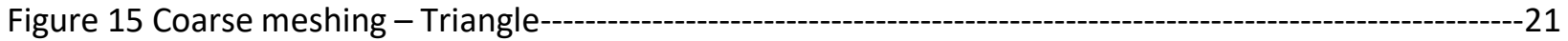

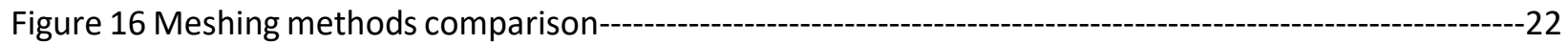

Figure 17 Triangle meshing comparison------

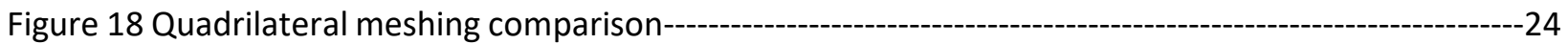

Figure 19 Triangle Fine Meshing - Stress distribution A) X direction B) Y direction C) Z direction------------25

Figure 20 Triangle Coarse Meshing - Stress distribution A) X direction B) Y direction C) Z direction--------25

Figure 21 Quadrilateral Fine Meshing - Stress distribution A) X direction B) Y direction C) Z direction-----26

Figure 22 Quadrilateral Coarse Meshing - Stress distribution A) X direction B) Y direction C) Z direction-26

Figure 23 Point $A: Z$ displacement imperfection comparison---

Figure 24 Point $B: Z$ displacement imperfection comparison----

Figure 25 Point $C: X$ displacement imperfection comparison---

Figure 26 Circular $Y$ Direction - Stress distribution (1.5 inch radius)-----------------------------------------------30

Figure 27 Circular X Direction - Stress distribution (1.5 inch radius)------------------------------------------30

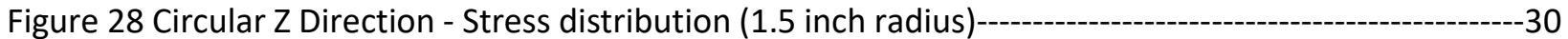

Figure 29 Shape of the hole A) circular (Madenci \& Guven, 2006) B) Diamond C) Rectangular E) Double Diamond--------------------------------------------------------------------------------------------------------31

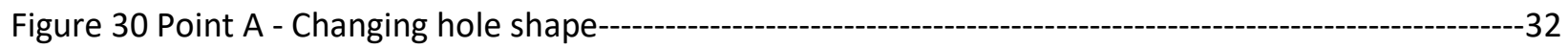

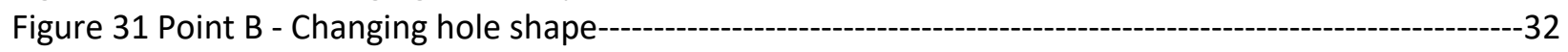

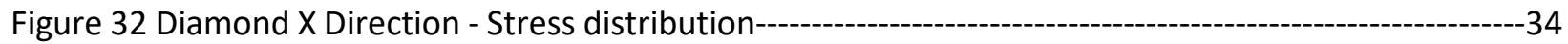

Figure 33 Diamond Y Direction - Stress distribution------------------------------------------------------------34

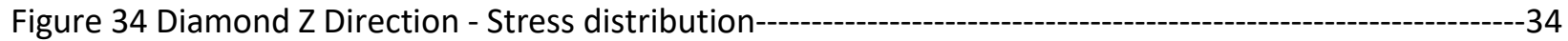

Figure 35 Double diamond X Direction - Stress distribution----------------------------------------------------------35

Figure 36 Double diamond Y Direction - Stress distribution----

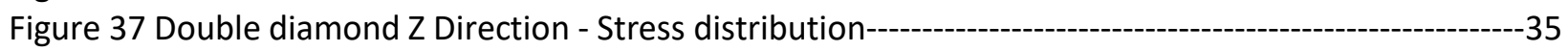

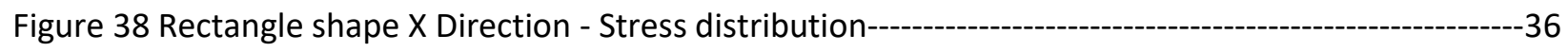

Figure 39 Rectangle shape $Y$ Direction - Stress distribution-------------------------------------------------36

Figure 40 Rectangle shape Z Direction - Stress distribution---

Figure 41 Point $A$ - Changing size of the hole---

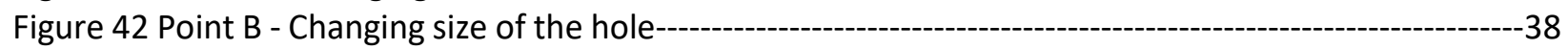




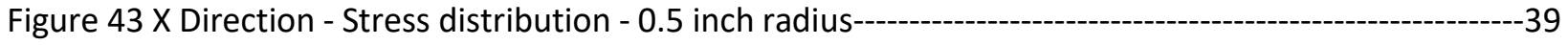

Figure 44 Z Direction - Stress distribution - 0.5 inch radius-------------

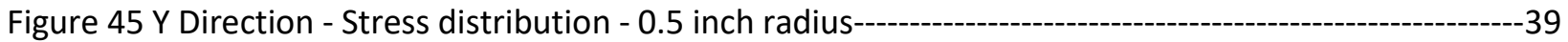

Figure 46 Figure $35 X$ Direction - Stress distribution - 2.5 inch radius-----

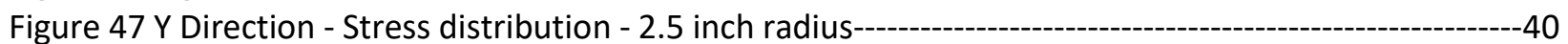

Figure 48 Z Direction - Stress distribution - 2.5 inch radius-- 


\section{Introduction}

Finite element analysis is a numerical process that can be used to simulate the response of structures and find estimated solutions for complex engineering problems. Simulations done using Finite Element Model (FEM) have gained great attention among engineers and researchers.

Recent FEM software are extremely accurate. However, it is the experience of engineers that provide accuracy and not the software. Without proper knowledge of the project and FEM, achieving acceptable results can be difficult no matter how accurate the software is. The engineer must be able to get accurate inputs of geometry, properties of the material, physics, loads, and other factors. ANSYS Parametric Design Language software or APDL is a commercially available FEM program that outrivals when repeated calculation with changing variables is needed. Using commands makes it convenient to developed loops and repeat actions, such as simulating hundreds of load cases and automatically write out only few numbers for each set.

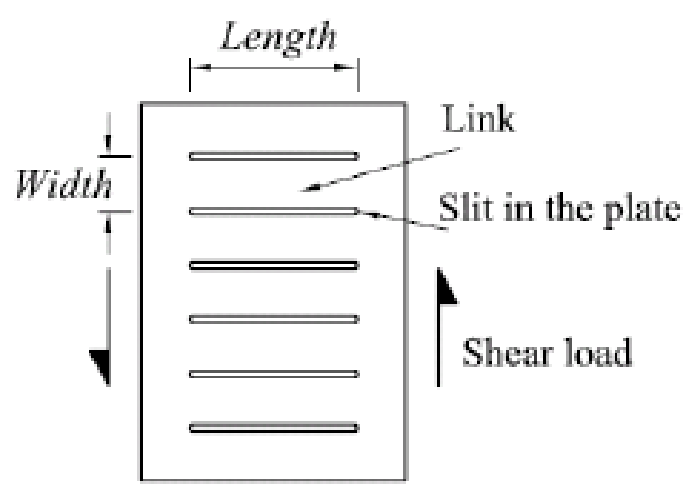

Figure 1 Fuse with links (Xiang, et al., 2011)

The objective of this report is to investigate the effects of changing different inputs, such as plate imperfection or out-of-straightness value, shape and size of the fuse openings, and different meshing types on yield strength, deformation, stress distribution, and displacement of the steel plate by using ANSYS Mechanical APDL. One of the recent applications of steel plate fuses is in controlled rocking systems during seismic event [ (Moradi, Burton, \& Kumar, 2018)], and this is achieved by devising a controlled rocking system which significantly reduces or even eliminates residual drifts by concentrating majority of structural damage in replaceable steel plate fuses. In other wards structural fuses are used to protect the structure from damage and could be then replaced after a major earthquake. 
To achieve high ductility while also being cost effective (Chan \& Albermani, 2008), steel plate fuses are created with openings, i.e. cuts into the plate dividing it into sections of parallel links as shown in figure 1. Links are more flexible and more compact compared to the original solid plate. This report looks into benefit of using links and its effect on yield strength. 


\section{Literature Review}

The study by Deierlein (2008) looks into the results from a half-scale test conducted at the University of Illinois. The study examined the behaviour of a controlled rocking system. The system consisted of a stiff steel braced frame that is not tied down to the foundation, a vertical posttensioning strands that anchor the top of the frame to the foundation and a replaceable structural fuse that absorbs seismic energy. The study's main objective was to check if this controlled rocking system is achievable and if the replaceable fuse alternative is appropriate. The controlled rocking configuration used in the study was shear fuse panel. The study suggested that the fuse should be designed with sufficient ductility and toughness that it can disperse energy throughout the cyclic loading during earthquakes.

The study verified that the controlled rocking system has exceptional energy dissipation capabilities when coupled with self-centering features. The vertical posttensioning successfully transferred the selfcentering forces, and the replaceable fuse left the braced frame essentially elastic. The paper concludes that the controlled rocking system was able to eliminate outstanding drifts while concentrating structural damage in replaceable fuse elements.

In order reduce the damage caused to the structure, the structure's ductility demand should be decreased, as well as it's hysteretic energy demand; in other words, the ductility and hysteretic energy capacity should be increased (Symans MD, 2008). When a metallic yielding device is added, the reduction in the ductility demand is given by reducing the displacements that results from the increased stiffness of the system or from hysteretic energy dissipation within the devices. The degree to which energy dissipation devices are able to dissipate energy depends on the native properties of the basic structure, the properties of the device, the connecting elements, and the ground motion. The hysteretic energy dissipation demand on a critical component of the structure can be reduced by transferring the energy dissipation demand to the passive energy dissipation devices.

In addition to passive energy dissipation devices there are active, semi-active and hybrid energy dissipation devices. Paper by Soong \& Spencer (2002) outline development of those devices as well as their advantages and limitations in the framework of seismic design. Active, semi active and hybrid devices are force transferring devices combined with processing regulators and sensors within the structure. They act at the same time with an unsafe excitation, to enhanced structural behavior for improved serviceability and safety. 
Active energy dissipation systems have sensors that measure external forces, and/or structural response variables. Based on a previously specified control algorithm, the devices process the information from the sensors and compute the control forces required. The final element of the active energy dissipation systems is the actuators. Actuators produce the needed force and they are usually powered externally. Actuators are usually very large in active systems and smaller in the hybrid and semi-active types.

Among the advantages of using active energy dissipation devices are the system's insensitivity to ground motion and site condition. There is an enhanced effectiveness in response to external force when using active systems, its efficiency is controlled by the capacity of the control systems. Active systems can be used for motion control for both wind and seismic forces. Finally, there is the ability to selectively change the control algorithm to prioritize different purposes, for example prioritizing comfort during calm weather and structural safety during earthquakes.

Hybrid energy dissipation systems mostly refer to combined passive and active control systems. Since a portion of the energy dissipation is accomplished by the passive system, there is less active control energy, therefore requiring less power resource. Figure $2 \mathrm{~A}$ shows how a hybrid system usually functions. In semiactive energy dissipation systems, the bounded input and output forces are guaranteed as the actuators do not add mechanical energy straight to the structure but to the passive device. Figure $2 \mathrm{~B}$ shows how the semi-active system works. Semi-active control devices are seen as adjustable passive devices. One of the main advantageous of using hybrid or semi-active control systems to active ones is that in the case of a power outage, the passive mechanisms of the control system can still offer some degree of protection. 
A)

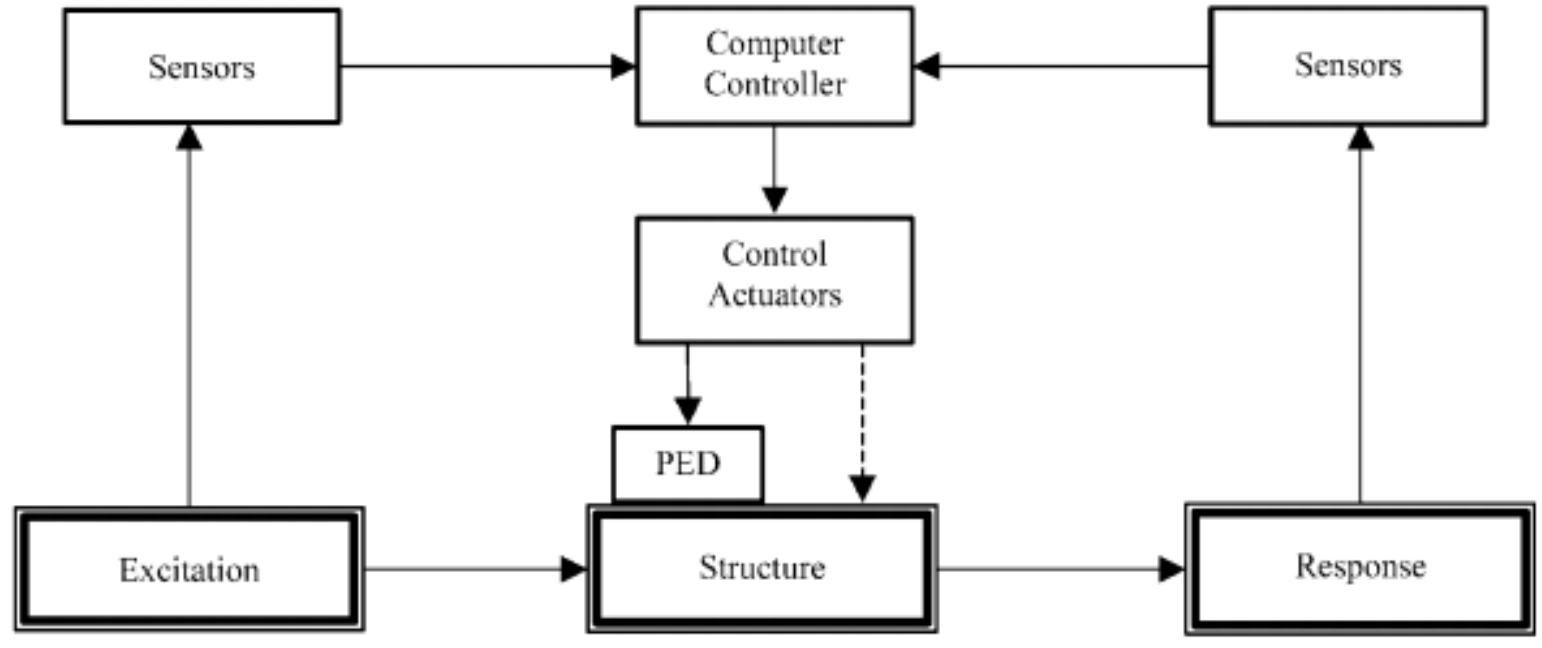

B)

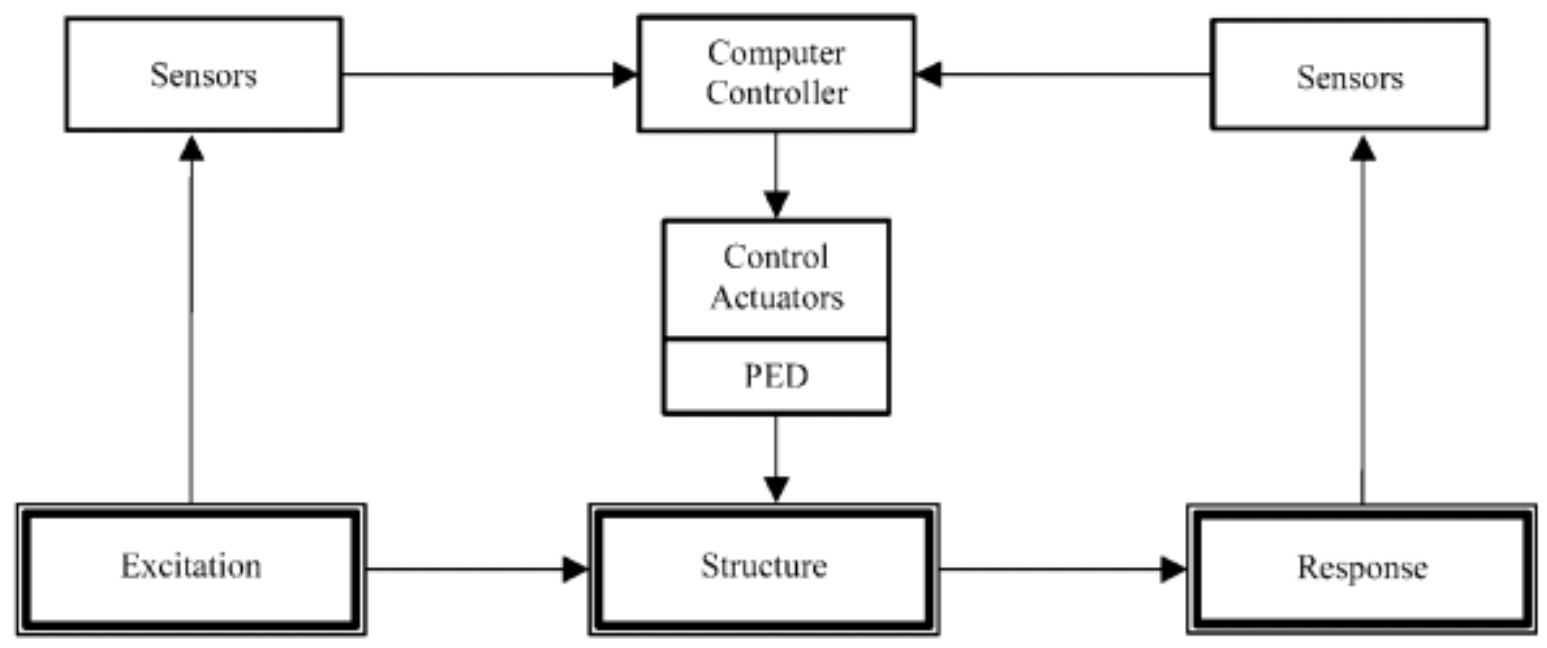

C)

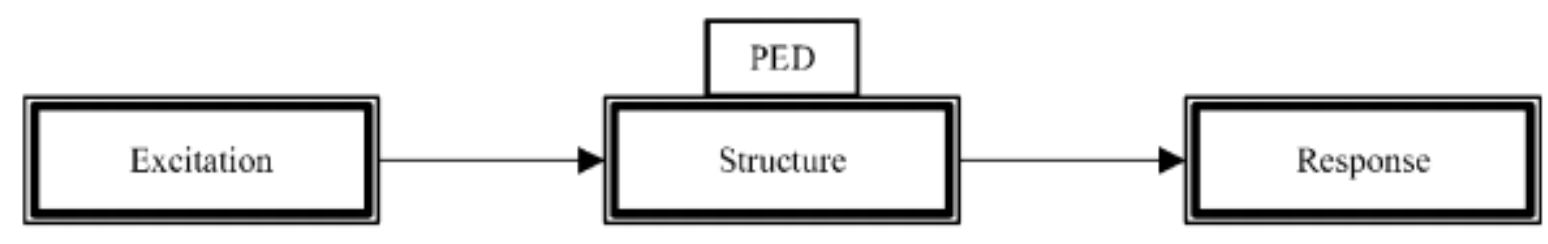

Figure 2 A) Hybrid energy dissipation system B) Semi-active energy dissipation systems C) Passive energy dissipation system (Soong \& Spencer, 2002) 
The article by Symans MD (2008) discusses different passive energy dissipation systems and their application to building structures for seismic response control. The study examines different types of dampers and discusses their advantages and disadvantages. The first type is the viscous fluid damper; it results in a horizontal oval shaped hysteretic behaviour as shown in figure 3A. Advantage of using the viscous fluid damper is that it could be activated at low displacements, it requires minimal restoring force, and it is a temperature independent system. Its disadvantage is that the fluid seal might leak making it unreliable in some cases. This type of dampers is very common in military applications. The second type of dampers analysed is the viscoelastic solid damper, it results in narrow diagonal oval hysteretic behaviour as shown in figure 3B. Similar to the viscous fluid damper, this type could also be activated at low displacements, and it provides restoring force. Its disadvantage is that it is temperature dependent, it has limited deformation capacity, and there is also a possibility of its material debonding.

A)

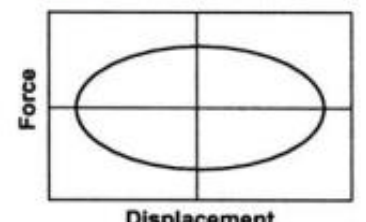

Displacement
B)

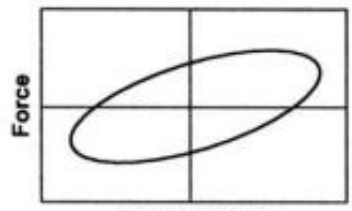

Displacement
C)

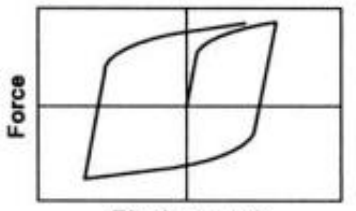

Displacement
D)

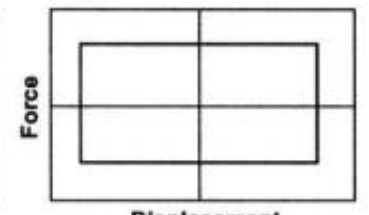

Displacement

Figure 3 Hysteretic Behaviour of A) Viscous fluid damper B) Viscoelastic solid damper C) Metallic damper and D) Friction damper (Symans MD, 2008)

The third type of dampers is the metallic damper, which is studied in this project. A metallic damper forms a butterfly shaped hysteretic behaviour, as seen in figure 3C. Its advantages beside having stable hysteretic behaviour is its long term reliability, insensitivity to high temperatures, and its easy replaceability.

The fourth type of dampers is a friction damper, which results in a rectangle shaped hysteretic behaviour as shown in figure 3D. This type of dampers can dissipate large energy per cycle and it is insensitive to high temperatures. Its disadvantage is that its sliding configuration may change with time, and it could result in permanent displacement if there was no restoring force device added.

Kobori, et al. (1992) studied the behavior of a honeycomb damper system to reduce the seismic response of high-rise buildings and towers. The honeycomb damper formed a butterfly shaped links by cutting the plate into honeycomb shaped holes. The study results showed that due to the plate geometry resemblance to moment diagram of deforming beams in double curvature, the yielding was evenly distributed along the length of the links. 
The study by Bayat \& Abdollahzadeh (2011) investigates the behaviour of structures with and without energy dissipating devices. The study discusses energy concepts under near field records, taking three cases for the analysis, including structures with five, ten and fifteen story concentric braced frames. Near field ground motions, such as the 1994 Northridge, the 1999 Chichi Taiwan and the 1995 Kobe earthquakes resulted in severe damage to structures. These motions are characterized by high level of peak ground acceleration, large vertical ground wave, and an intense long duration of high velocity pulse waves. Taking those records into consideration, the paper highlights the importance of a well designed energy dissipation device.

The study uses the FEM software PERFORM 3D to simulate the fuse and frame. The frame was built in accordance to Uniform Building Code 97 requirements for static analysis, with structure being in zone 4. The effect of changing the structure's height is simulated as well as effect of adding the energy dissipated device. Results of changing height showed that input energy increases in the braced frame system as the height increases, and it decreases when adding energy dissipation device. The study results showed that the performance of structures with energy dissipated devices under near field records are better than those without any energy dissipation devices. The addition of the dampers significantly increased the resistance of the structure to dynamic loading and it also helped in reducing the seismic response of the structures.

The study by Symans MD (2008) analysed two frame systems, one with a passive energy dissipation device and one without; Figure 4 shows those two structures. The frames were subjected to a single historical earthquake record. Two different types of devices were considered in the study, a metallic yielding device and a viscous fluid device. Varying strengths and capacities of the two devices were analysed in the study.

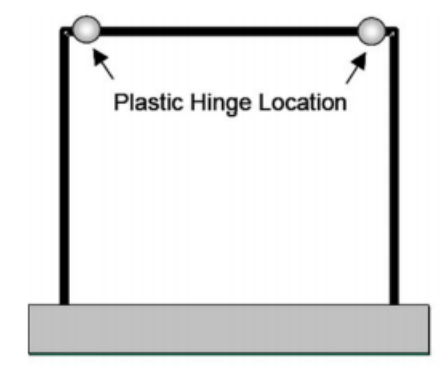

(a)

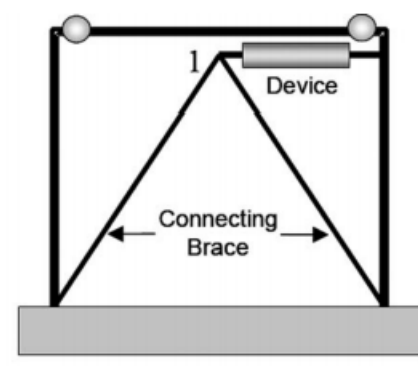

(b)

Figure 4 A) Structure without passive energy dissipation B) Structure with passive energy dissipation (Symans MD, 2008) 
The study classifies metallic yielding devices into two categories: rate-dependent devices, and rate independent devices. Rate dependent devices are those that are depend on the rate of change of displacement across the damper. Rate independent devices are those that depend on the magnitude of the displacement.

The results of the metallic yielding device showed that with each increase in device strength and elastic stiffness, the elastic period of vibration in the structure decreases. The ductility, energy dissipation demand, and damage to the device decrease significantly with increase in the capacity of the device. Results for fluid damping device showed that the elastic period of vibration of the structure did not change with the added viscous damping. The viscous damping device has insignificant stiffness under low frequency response. Unlike the metallic yielding device, the fluid damping device have no self-centering capability, therefore the structure is behaving inelastically. Tests showed that the damping force increases as the damping coefficient and the velocity increases. The study concludes that both the metallic yielding and fluid viscous damping devices were highly effective in reducing damage to the structure. But, this comes at the expense of increasing base shear and foundation costs.

A paper by Deng, Pan, Sun, Liu, \& Xue (2014) discussed methods to optimize steel shear panel dampers for improving low cycle fatigue. The paper used the shape of steel dampers as a variable in the optimization process. The study assumed that the low cycle fatigue has a negative relationship with the maximum plastic strain in the loading process. The paper used the finite element analysis software ABAQUS to find the plastic strains, different aspect ratios and shapes. Several control points were chosen on the free boundary in order to acquire the shape of the energy dissipation zone as shown in figure 5. The study used 2 main basic theories of solid mechanics in their optimization process. First is that the stress concentration on the mutation point doesn't allow mutation of the first derivative of the free boundary. Second is that in order to lighten the stress concentration, the second derivative ought to be continuous. The optimal position of the control points corresponds to the ideal shape of the energy dissipation zone. Two of the main conclusions from the study are that: shape optimization can greatly improve the low cycle fatigue performance of the steel shear panel dampers; and after optimizing the shape of the steel shear panel dampers, the dampers exhibited small decrease in their energy dissipation ability. 


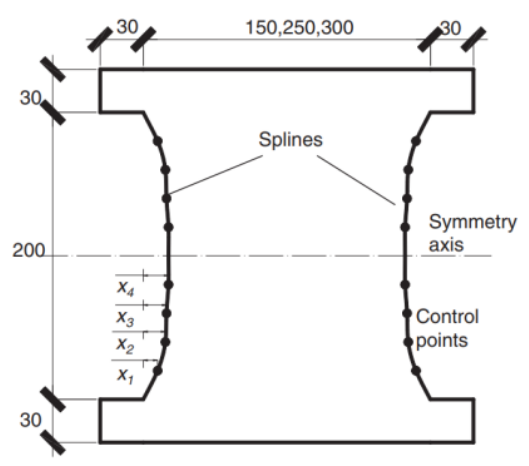

Figure 5 Steel shear panel dampers used in Deng, Pan, Sun, Liu, \& Xue (2014) study.

The research project by Ma, Krawinkler, \& Deierlein (2011) studies two types of fuses, one slit fuse with narrow slits that divide the plate into rectangular links and the other butterfly fuse that divide the plate into butterfly shape links. The steel shear plate fuses were tested under cyclic loading using similar controlled rocking systems as in Deierlein, et al. (2008). The shaking table test results showed that the system responded to earthquake load with uplifting of columns and a rigid body frame rotation. The research project results show that the butterfly shaped steel fuse emerged as a high performance system based on its behavior, compatibility with rocking frame system, and its simple design. During the shaking tests, the fuses were used for five to nine cycles without any indication of cracks, and they displayed adequate ductility during the test.

The study by Chan \& Albermani (2008) looks into the performance of steel slit fuse and the effects of its geometrical parameters when subjected to inelastic cyclic deformation. The study first analyses the fuse's behavior theoretically, and verify its findings experimentally using eight cyclic tests and one monotonic test. The fuse studied in the paper made of slit cuts with rounded ends to reduce stress concentration on slit ends, the shape studied is similar to the one in figure 1 . The fuse is connected to the structure by four bolts on each of its flanges. The plate is expected to deform in double curvature acting as partially fixed beams under displacement between the two flanges.

During the experimental test, the authors paid attention to two key factors, including change in stiffness and damping ratio. The study used 9 plates in their tests with various slit thickness and length. The tests showed that the plates deformed in a stable manner and in double curvature as hypothesized. The nine plates yielded at small displacements and had stable hysteretic behaviour. The plate with smallest thickness to length ratio sustained the least force, while the one with highest ratio sustained the most force. Tests showed that plates with the highest rate of energy dissipation were the ones with least 
slenderness, but they also failed at low cumulative displacement. In terms of stress distribution, the tests showed that the loading is uniformly distributed between all strips in the plate. By studying the damping ratios, the paper concluded that the effective stiffness decreases as displacement increases. When there was large displacement, the plates provided damping ratio exceeding 50\%. Generally, the average damping ratio was between $30 \%$ and $50 \%$. The study showed that due to strain hardening, the ultimate strength of the plates was larger than their yield strength by a factor of 2 , this means a larger margin of safety when greater energy dissipation is needed.

The study by Lee, Ju, Min, Lho , \& Kim (2015) looked into three different shapes of steel plate dampers. The shapes were designed in order to reduce stress concentration when subjected to cycle loading. The three shapes that were compared to prismatic slit dampers were dumbbell shaped strip, a tapered strip, and an hourglass shaped strip; the four shapes are shown in figure 6 . The paper studied the structural features of the steel plate dampers such as elastic stiffness, yield strength, plastic strength, ductility and energy dissipation capability. The study focused on flexure strip fuses only, as the height to width ratio of the fuse increases the flexure force is the one that governs the behavior of the fuse.

For simplicity, the study considers strips with fully restrained ends as a beam model with fixed ends. With this assumption, several equations were calculated for the theoretical analysis; such as the plastic moment, width of the strips, yield strength, elastic stiffness and yield displacement. For the experimental analysis, the three plates were designed to be connected without welding but with high tension bolts, and cyclic loading with incremental load was applied to the plates. Failure in the plate occurred in forms of cracks on sides of the plates followed by a sudden failure caused by gradual strength degradation. The prismatic slit dampers and the hourglass shaped strip showed deformation in the plane direction of the plate. For large amplitudes, dumbbell shaped strip and tapered strip displayed out of plane behaviour, this was a result of their low out of plane stiffness.

A)

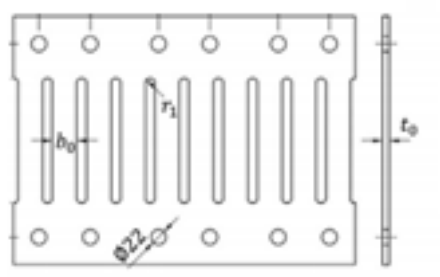

B)

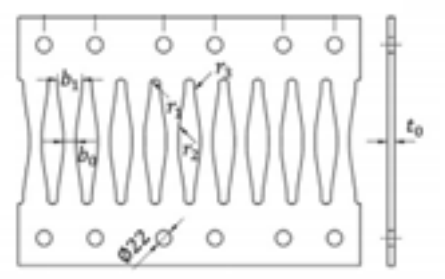

C)

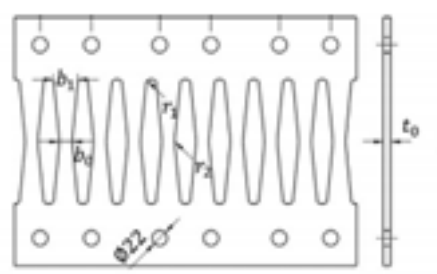

D)

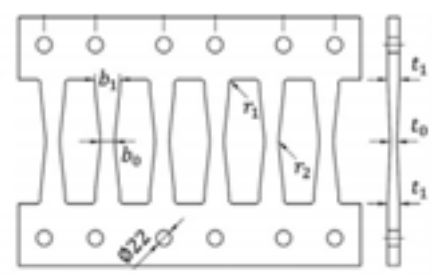

Figure 6 A) Prismatic slit dampers B) Dumbbell shaped strip C) Tapered strip D) Hourglass shaped strip (Lee, Ju, Min, Lho , \& Kim, 2015) 
The results showed that the three proposed dampers greatly improved ductility as well as energy dissipation compared to the conventional strip damper. The plates were also able to absorb a substantial amount of added energy even after they have failed. The calculated strength based on flexure agreed with the experimental results verifying the equations. For the strain analysis, only one internal strip was measured, as external load is uniformly transferred to each strip. The experimental test confirmed that the strains in the strip occurred evenly as the boundary conditions at the top and bottom ends are equal. The study was successful in showing that the three proposed dampers have structural efficiency 2 to 3 times that of regular prismatic slit dampers in terms of energy absorption per unit volume. From the two studies by Chan \& Albermani (2008) and Lee, Ju, Min, Lho, \& Kim (2015), some common conclusions can be made. The longer or wider slits behave more flexibly, while narrower slits have higher stiffness and higher dissipation rate, but they experience earlier failure.

The study by Ghabraie, Chan, Huang, \& Xie (2010) used the Bidirectional Evolutionary Structural Optimization (BESO) method to optimize the shape of passive energy dissipation device. The paper used the shapes given in Chan \& Albermani (2008) as base for their study and use the BESO algorithm to further optimize the fuse. The study considered some restriction in their analysis to maintain the topology of the design. The study used an objective function of having the plastic energy dissipation after one cycle of displacement loading with $10 \mathrm{~mm}$ amplitude. The optimization problem used was maximizing the objective function while having the shape restrained and material volume constant.

After running the BESO procedures the results showed that the objective function values for plates displayed a substantial increase in the energy dissipation capacity. Improvements to energy absorption capacity ranged from $58 \%$ increase to $96 \%$. The optimized fuse had a diamond shaped slits with varying geometry. The study used finite element analysis to simulate their optimized plates. From FEM, it was clear that the optimized designs provided an even stress distribution. Where the initial straight slit design by Chan \& Albermani (2008) had noticeable stress concentration that has been eliminated in the optimized design. The study uses cyclic testing to verify their results and find accurate data for failure and fatigue of the plates. The authors used one of their specimens for testing and it showed that the optimized plate dissipated $37 \%$ more energy per unit volume compared to the previously tested steel slit damper. 
The study by Foti, Nobile, \& Diaferio (2013) evaluated a new type of passive energy dissipation device that has aluminum plate located in the middle of the device itself. The study required the plate to be stressed uniformly, and to concentrate energy dissipation in the plate's aluminum core. The proposed design is shown in figure 7 , as well as the placement of the plate in the structure.
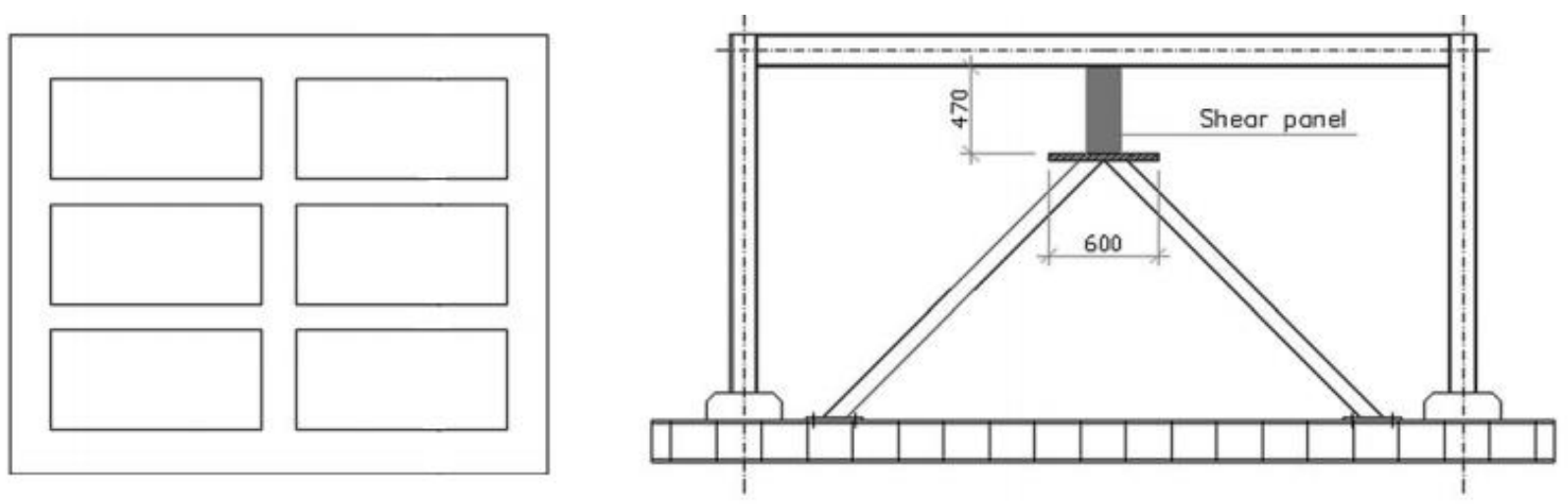

Figure 7 A) Proposed design by (Foti, Nobile, \& Diaferio, 2013) B) Placement of the aluminum plate

The authors when designing the plate had to satisfy two characteristics of any energy dissipation devices, first to limit displacement in the material, and to ensure that the device will display a ductile behavior in order to maximize energy dissipation. The design has been carried out assuming the plate is subjected mainly to shear forces. The study uses 1000 series aluminum alloy plate, as it has higher ultimate and yielding stresses compared to steel plates, and on each face of the aluminum plate two S235 steel plates were attached to limit out of plane instability. The steel plates have rectangular cuts in them, where aluminum plates become visible; this was done to ease load transmission between aluminum and steel. The three plates were then connected by bolts, and the plates was designed to be placed at each story between two diagonal bracing as shown in figure 7B.

The model was simulated using ANSYS with solid90 material element. The plate was optimized by having the objective function be to maximize the energy dissipation in the aluminum plate. Simulation showed that as transversal loading increases the panel width needs to be increased in order to dissipate energy. From simulation it was also concluded that the most fitting panel geometry depends on the shear force expected in the plate. Therefore, the study produces different geometries depending on the shear force required.

The study explains the approach required to find the value of this shear force and how to select the appropriate plate. First, one should disregard the plate and analyse the structure with the same diagonal bracing as with the plate. The maximum shear force is then found by seismic analysis of the braced 
structure. Finally, choosing appropriate aluminum energy dissipation device based on $20 \%$ higher shear force to ensure functioning of the device during a seismic event.

The study performed experimental tests on two plates, using a hydraulic actuator to apply shear load to the plates. The load from the actuator is divided equally to the panels. The test used load cycles in tension and compression. The test was initially stopped due to failure to the welding at the base of the panels and resumed when a folding steel plate was added to the base of the panel. Results of the test showed that the design proposed by the optimization procedure was satisfactory as the amount of energy dissipated by the device was well over $35 \%$ of the whole mechanical energy stored in the plate.

The paper by Kurokawa, Sakamoto, Yamada, Kurino, \& Kunisue (1998) describes how using passive energy dissipation devices made a $100 \mathrm{~m}$ tall building architecturally and structurally feasible. The building is unique because its design has a combination of a rectangular parallelepiped, and a quadrangular pyramid; the building contains a spacious atrium and a spherical hall. The complex building is made up of an office tower building, hotel tower and educational building. The building is shown in figure 8.

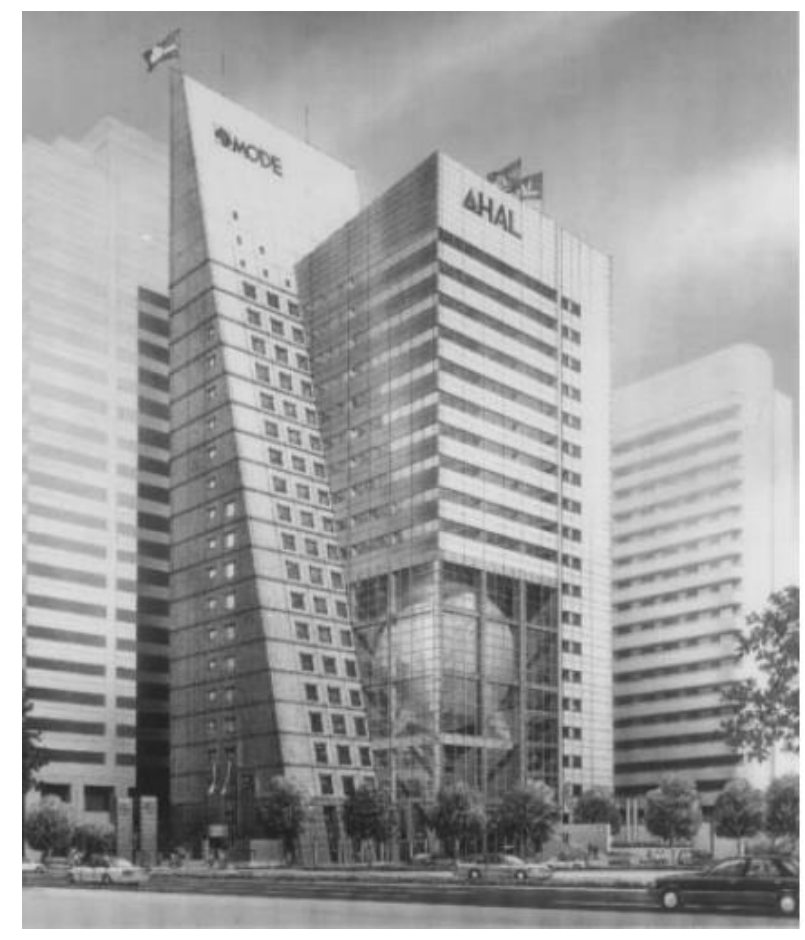

Figure 8 The tall building with passive energy dissipation devices (Kurokawa, Sakamoto, Yamada, Kurino, \& Kunisue, 1998) 
The paper proposed a honeycomb fuses that will be placed at the external frames of building between the vertical spans inside the studs. The fuses were designed to bear $10 \%$ to $18 \%$ of the static design story shear force up to the sixth floor, after which fuses were designed for higher shear force to compensate for the reduction in the number of columns due to the presence of the spherical hall. The steel plates used contained honeycomb cuts. The study underwent experimental tests to examine fuse behaviour, the test simulates the El Centro 1940 earthquake. The honeycomb fuse reduced the story shear force by $30 \%$, test also showed that the excessive deformation was prevented by the fuse. the study found that the plate started yielding at input of $5 \mathrm{cms}^{-1}$ while the frame started yielding at $25 \mathrm{cms}^{-1}$, this showed that seismic forces were concentrated in the fuse, leaving the structure intact.

The paper also studied the wind load effect on the honeycomb fuse. The fuse yields before the frames therefore it might be important to look into fatigue failure due to wind loads. First time history wave forms in both windward and leeward directions were calculated. The paper then ran elastoplastic response analysis using the time history data. The analysis showed that if a 100 -year serviceable time is assumed then the probability of fatigue failure of the dampers is $19 \%$. Results showed that fatigue failure of the fuse due to wind load is not a critical factor to be considered in the design. The paper concludes by stating that the use of fuses in structures is a feasible option as they are low in cost, high in performance, they guard the structure from damage and can be easily replaced if failed.

Additional method to investigate the fatigue life of an energy dissipation device is proposed by Shin \& Kim (2018). Authors proposed using a simplified method to predict the low cycle fatigue life of passive energy dissipation devices, the study investigated the notch areas of the plates were stress is concentrated. The simplified method employs the damage measure and fatigue prediction equations which are based on the plastic strains found from simple FEM analysis without considering a complex fracture mechanism. The study verified results from simplified method using experimental harmonic cyclic tests. Results showed that the simplified method prediction were in good agreement with the test results and in small number of cases the prediction was conservative. The study found that energy dissipation devices with curved notches reduced fatigue damage by $40 \%$ compared to devices with sharped notches. They also delayed early development of plastic strains. The study also concludes that from experimental tests curved notch devices displayed strength degradation without fractures and with few discrete cracks compared to sharped notch devices.

To highlight the importance of well designed energy dissipation devices, the paper by Perri, Faella, \& Martinelli (2016) was examined. The paper looks into the behavior of cost competitive energy dissipation 
devices. The study aims to analyse devices that are used to retrofit ordinary structures, where budget restriction is a key deciding factor. The paper considered two devices to be placed as link element in diagonal bracing, similar to configuration in figure 7B. The paper studied the behaviour of the devices experimentally. Results showed that the plates had a sudden decay in shear reaction under cyclic displacement, plates also showed fast decline in lateral strength and stiffness. The specimens showed a significant hardening effect that was induced by the cyclic actions. The study concludes that the proposed plates are not sufficient for tall structures, and that further studies are needed before implementing those competitive plates.

Today there are many energy dissipation systems that have been installed in full scale structures for seismic dissipation. Some example structures that use active energy dissipation devices are: Kyobashi Seiwa Building, 11 story office building in Tokyo, Japan; Porte Kanazawa, a hotel with 30 floors in Kanazawa, Japan; Riverside Sumida, an office building with 33 stories in Tokyo, Japan; and Nanjing, a Communication Tower in Nanjing, China. Structures that use hybrid energy dissipation systems include: Hankyu Chayamachi Building, an office and hotel building with 34 floors in Osaka, Japan; Land Mark Tower, a hotel with 70 floors in Yokohama, Japan; Osaka Resort City 200, a hotel with 50 floors in Osaka, Japan; Shinjuku Park Tower, a hotel and office building with 52 floors in Tokyo, Japan; TC Tower, an office building with 85 floors in Kaoshiung, Taiwan, and Kansai International Airport in Osaka, Japan (Soong \& Spencer, 2002).

Example structures that use semi-active energy dissipation systems include: Kajima Shizuoka Building, an office building with 5 floors in Shizuoka, Japan; Kajima Research Laboratory in Tokyo, Japan; and Highway I-35 Bridge in USA. Buildings that use passive energy dissipation systems include: Stockton Hotel, hotel with 6 floors in CA, US; Torre Mayor Tower, an office building with 55 floors in Ciudad, Mexico; Wallace F. Bennett Federal Building, an office building with 8 floors in Utah, US; Patient Tower, an office building with 14 floors in Seattle, US; and Kaiser Santa Clara Medical Center, a 4 story hospital in Santa Clara, California, US (Soong \& Spencer, 2002).

Unlike previous papers that study the implementation of fuses in buildings, the paper by ElBahey \& Bruneau (2011) studies the use of structural fuses as part of multicolumn accelerated bridge construction. Three span continuous bridge models were developed having two twin column pier bents with double composite rectangular columns and structural fuses. The first bridge used a shear steel plate link between columns, while the second used buckling restrained braces. The test was first conducted up to when the columns yielded, in order to examine the benefits of adding the fuses in dissipating the seismic energy. 
Then the test continues up to failure of the composite columns. Results of the study showed that both models displayed stable force-displacement behavior, until the substantial build-up of damage at larger drifts. By using the structural fuse, the columns remained elastic and seismic energy dispersion was limited to the structural fuses.

As the need for a replaceable steel fuse grows and the acceptability of controlled rocking system increases, the need to model those fuses becomes important. Using FEM to simulate the steel plate response allows engineers to optimize the fuse. By changing different parameters, a cost effective fuse that is easy to manufacture, mount and replace could be realized. This report highlights the effects of different inputs such as imperfection, shape and sizes of the fuse openings, and different meshing types using finite element modeling of steel plate fuses under monotonic loading. 


\section{Finite Element Model}

The steel plate specimen discussed in (Madenci \& Guven, 2006) was used for this study. The specimen consisted of a 9.5 in-square composite plate with a circular hole of radius $1.5 \mathrm{in}$, with total laminate thickness of 0.12 in consisting of 12 layers where each layer has moduli of $\mathrm{E}_{\mathrm{L}}=18.5 \times 10^{6} \mathrm{psi}, \mathrm{E}_{\mathrm{t}}=1.6 \times 10^{6} \mathrm{psi}, \mathrm{G}_{\mathrm{LT}}=$ $0.832 \times 10^{6}$ psi and Poisson's ratio of 0.35 .

Figure 9 shows the specimen mentioned in (Madenci \& Guven, 2006) as well as geometry details used. The displacement along 3 points $A, B$, and $C$ is monitored. Variation of $Z$ displacement of point $A$ and $B$, and $\mathrm{X}$ displacement of $\mathrm{C}$ is found and compared to the force displacement graph from (Madenci \& Guven, 2006) for the validation of the finite element analysis.

Figure 10 shows a render of the specimen; the meshing size for inner circle used is 5 divisions while the steel plate fuse used 10 divisions. Along the right side of the fuse, an axial concentrated load of 12,000 lb is applied through a fixed end. The fuse is fixed in all degrees of freedom including rotation and displacement along left side. In-plane displacement and rotation are allowed along the top and bottom horizontal sides. In order to initiate buckling and out-of-plane deformation, a sinusoidal imperfection with an amplitude of $1 \%$ of the total plate thickness is applied.

Several factors had to considered and modified in the FEM software. To represent the fuse, shell elements were chosen. Shell elements are suitable for modeling thin to thick walled structures. Beside showing good characteristics in bending and deformation, shell elements require minor computational power. Between different types of shell elements, SHELL181 was used for its layered application, and for its 6 degree of freedom at each of its nodes. Using the MP command in ANSYS, the material's properties were defined, $\mathrm{E}_{\mathrm{L}}=18.5 \times 10^{6} \mathrm{psi}, \mathrm{E}_{\mathrm{t}}=1.6 \times 10^{6} \mathrm{psi}, \mathrm{G}_{\mathrm{LT}}=0.832 \times 10^{6}$ psi and Poisson's ratio of 0.35. After forming the fuse, a centered circular hole of radius 1.5 inch was detached from the fuse and the fuse was meshed. Different meshing types were studied, and line sizing was chosen with inner circles having 5 divisions while the steel plate fuse having 10 divisions. Different line divisions have been examined before deciding on the final meshing. Those divisions have been chosen as they show the most accurate results in comparison with the reference curves. Another issue that came up during the modeling was creating imperfection in the model. The way that was solved was by having a loop that centered about getting different nodes coordinates, applying the imperfection then redefining it and moving to the next node. Getting the data from the FEM also required a loop that gave the selected nodes displacement and force in a table format. 


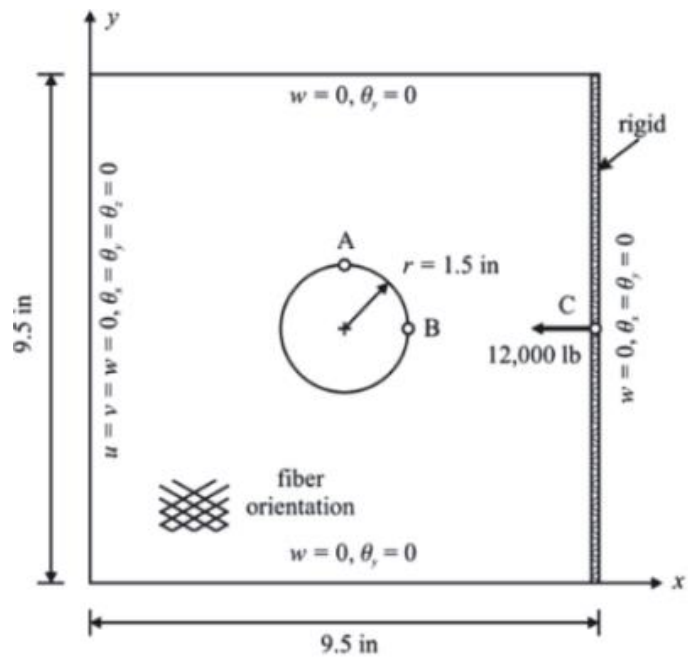

Figure 9 Composite plate (Madenci \& Guven, 2006)

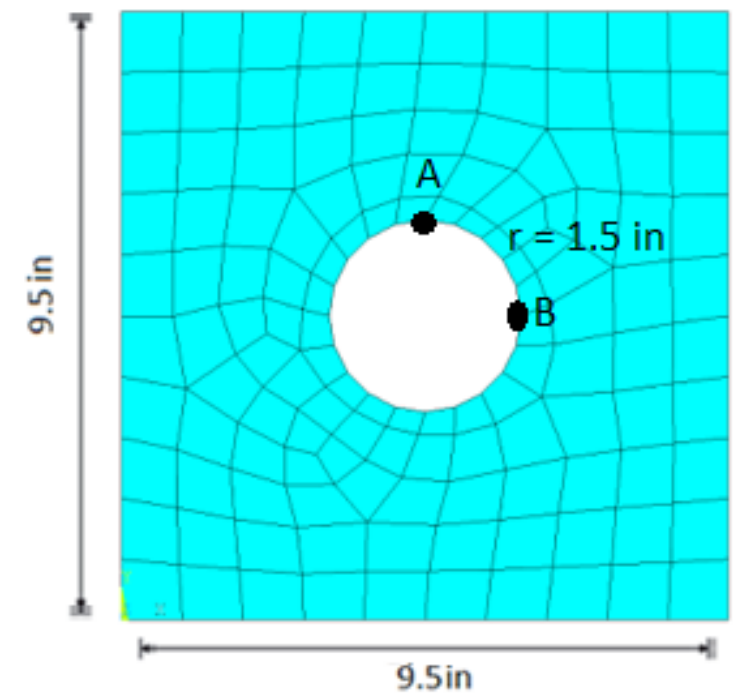

Figure 10 Meshed plate from FEM

Figure 11 shows a comparison of the force-displacement behavior obtained from the FEM overlaid with the reference curve. The model captured the behavior well with a slight difference at $600 \mathrm{lb}$. This could result from rounding numbers, and meshing; different method of meshing effects the results differently and will be discussed later in the report. 


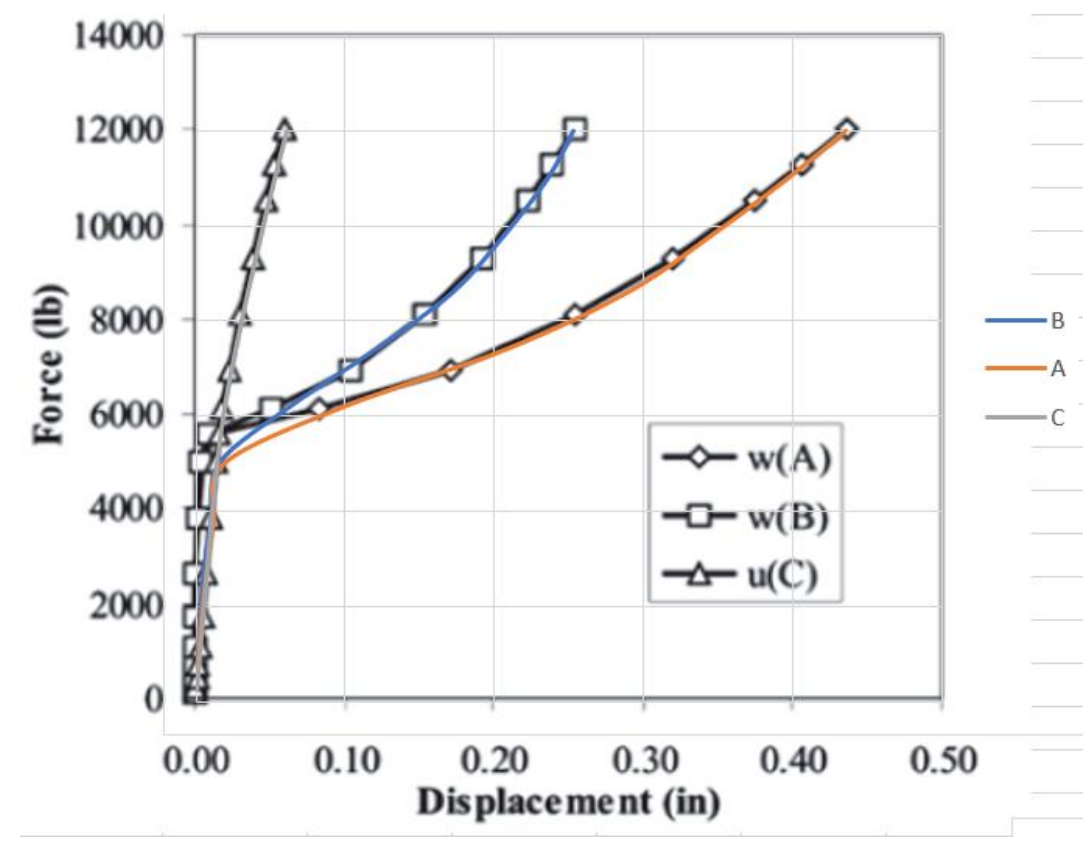

Figure 11 Verification of finite element modeling

As observed from figure 11, all points share the same linear slope until yield point (which is $4800 \mathrm{lb}$ for point $A, 5000 \mathrm{lb}$ for $B, 5500 \mathrm{lb}$ for $C$ ) after witch point $A$ shows higher displacement reaching up to approximately 0.45 inch at load $12000 \mathrm{lb}$. Point B showed lesser displacement response having last few points of $9813 \mathrm{lb}$ to $12000 \mathrm{lb}$ between 0.21 to 0.25 -inch displacement. Point $\mathrm{C}$ for $\mathrm{X}$ displacement showed least curvature reaching 0.061 inch at $12000 \mathrm{lb}$. 


\section{Effects of Meshing}

Now that the model is validated, different input parameters will be changed and their effect on the response curve will be examined. First, the influence of changing the mesh will be investigated.

The accuracy that can be attained from any FEA model is directly related to the finite element mesh that is used. The main purpose of meshing is to approximate a geometric domain of structures. Meshing stage for an FEM software can take up a long time, therefore a good understanding of meshing is important for productivity. This section will show the importance of different meshing types and accuracy of the analysis with each meshing type.

Two different mesh shapes will be looked at, including triangle and quadrilateral. Quadrilateral meshing could be formed using the auto shape meshing or using line meshing with specific divisions; in this report, quadrilateral meshing will refer to as auto shape meshing. Each of the two shapes will be divided into two sizes, fine meshing, and coarse meshing. Figure 12 shows fine meshing for quadrilateral, while figure 13 shows coarse meshing for the quadrilateral type. Figure 14 shows the triangular fine meshing while figure 15 shows the coarse mesh. The points that will be analysed for displacement are shown in Figure 9. For point A, displacement UZ will be studied, for point $C$, UX will be studied and compared with line meshing in figure 2. Finally, for point $B, U X, U Y$ and $U Z$ will be recorded.

Figure 16 shows the difference between line meshing method (meshing by resizing lines), triangles and quadrilateral meshing in comparison with the reference curves. As it can be noted from Force/Displacement graph, line meshing showed the best accuracy. For comparison with line meshing, points $A$ and $B$ demonstrate $Z$ direction behavior while point $C$ shows the $X$ direction. Line meshing in point A (purple line) overlaid with reference curve, followed by quadrilateral meshing (yellow line). Triangle meshing in point $A$ (dark blue) showed imprecise results with much smaller displacement. For point $B$, line meshing (brown line) again overlapped with reference curve, while triangle meshing (orange line) showed smaller displacement, and quadrilateral meshing (light blue line) showed slightly more displacement. For point $C$, Line meshing (dark gray line) presented best fit to reference curve nearly overlapping, followed by quadrilateral meshing (green line). Triangle meshing for point A (light gray line) showed smallest displacement and least accuracy. Overall, triangular meshing showed skewed results from the rest in the $Z$ direction (points $A$ and $B$ ) and close to the other responses in the $X$ direction. All

methods share same initial linear elastic region, with yield strength shown in table 1 . Line meshing resulted in higher yield strength followed by quadrilateral and then triangle meshing. 


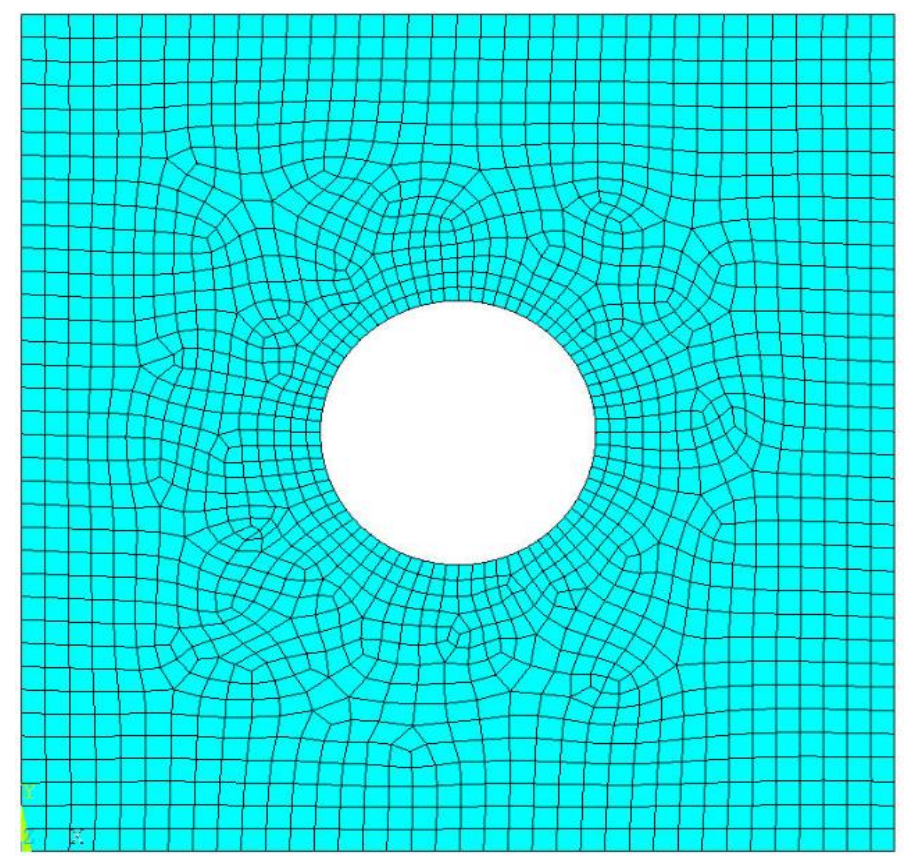

Figure 12 Fine meshing - Quadrilateral

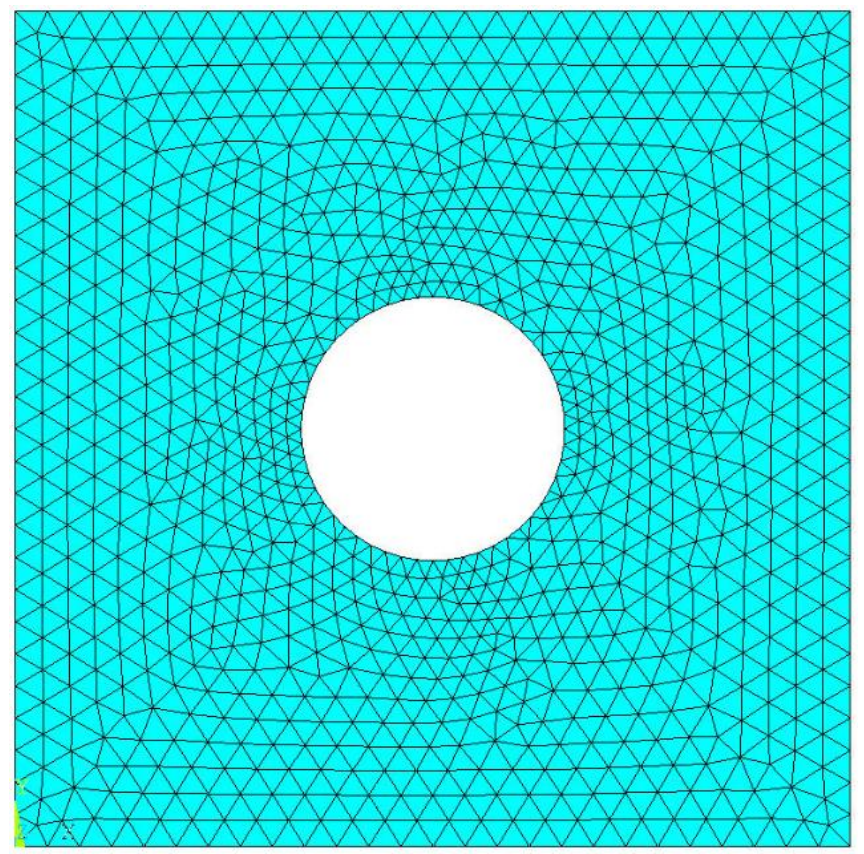

Figure 14 Fine meshing - Triangle

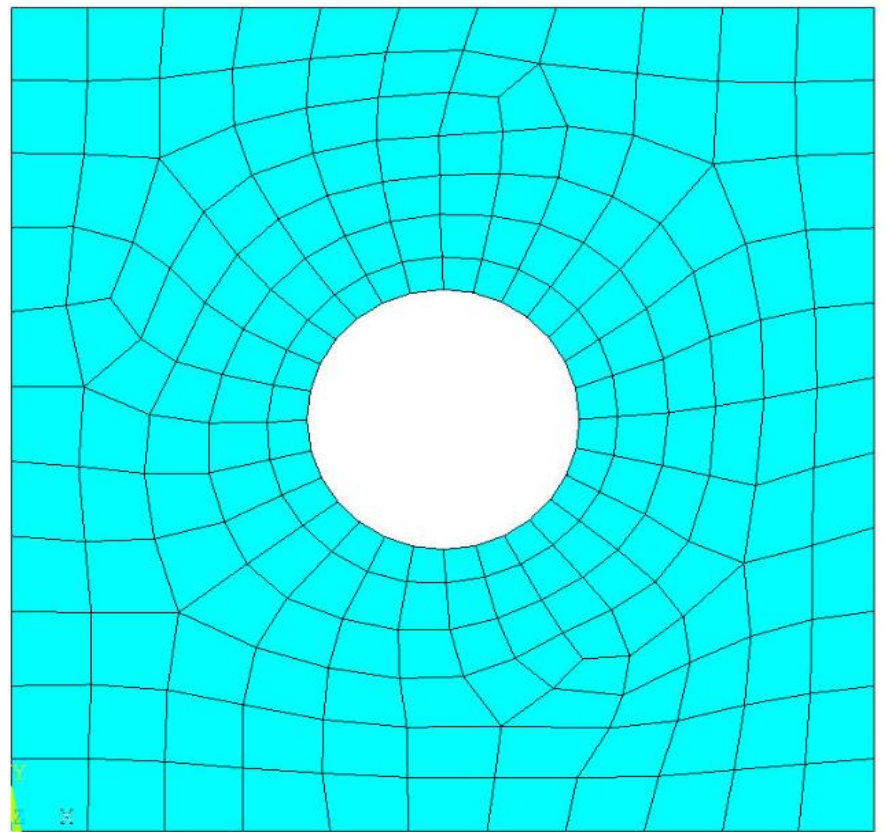

Figure 13 Coarse meshing - Quadrilateral

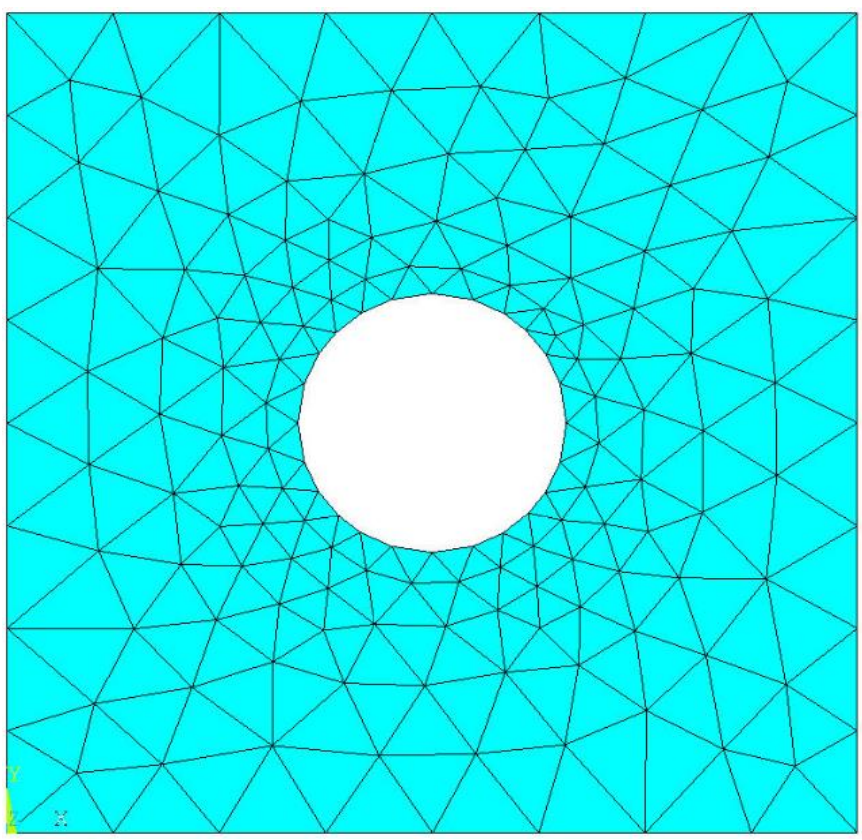

Figure 15 Coarse Meshing - Triangle 


\section{Meshing Methods}

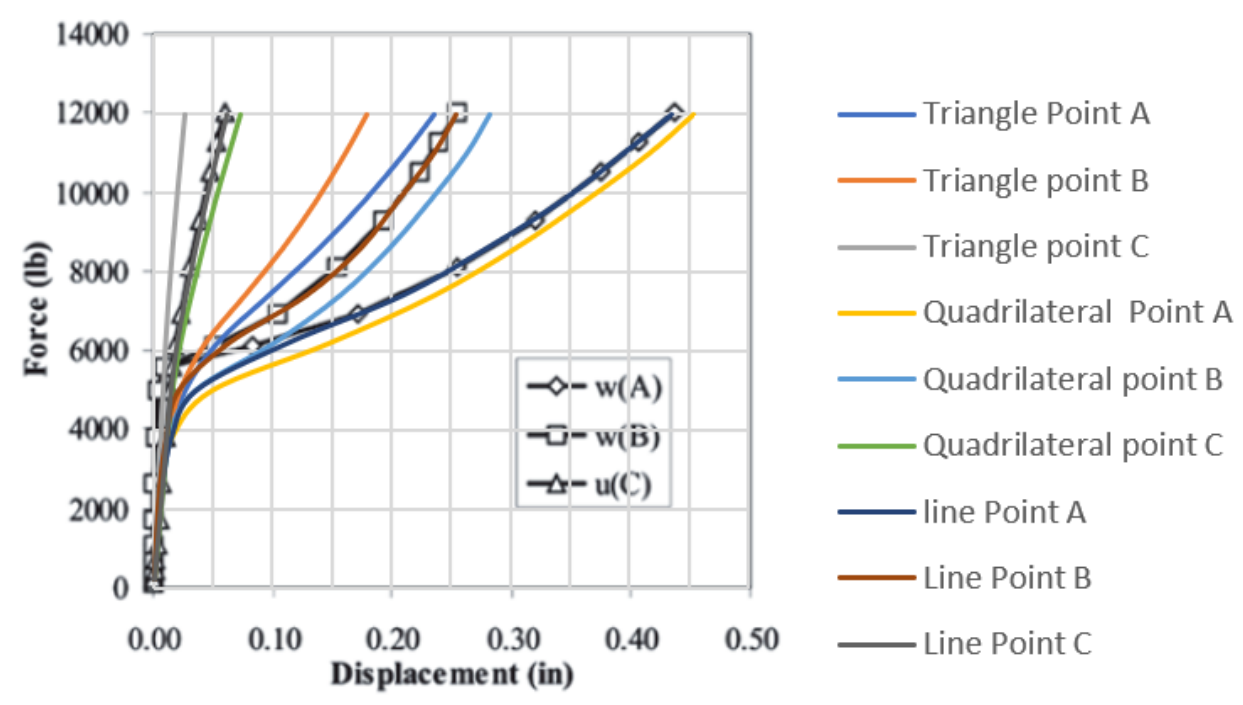

Figure 16 Meshing methods comparison

\begin{tabular}{|l|ccc|}
\hline \multicolumn{4}{|c|}{ Yield Strength (lb) } \\
\hline \multirow{2}{*}{$\begin{array}{c}\text { Type of meshing } \\
\text { method }\end{array}$} & \multicolumn{3}{|c|}{ Points } \\
\cline { 2 - 4 } & $\mathrm{A}$ & $\mathrm{B}$ & $\mathrm{C}$ \\
\hline Line & 4800 & 5000 & 5500 \\
Quadrilateral & 4200 & 4000 & 5300 \\
Triangle & 3800 & 4500 & 5000 \\
\hline
\end{tabular}

Table 1 Yield Strength - Meshing

For point A, triangular meshing showed a big variance from line and quadrilateral, having displacement of 0.24 inch compared to 0.43 and 0.45 inches for line and quadrilateral meshing, respectively. For point $B$, quadrilateral showed most displacement of 0.28 inch followed by line meshing with 0.254 inch and finally triangular with displacement of 0.18 inch. Point $A$ for triangular meshing showed less displacement than line and quadrilateral for points $B$, when it should have been more. Finally, for Point $C$ the three meshing methods showed close results with triangular, line meshing and quadrilateral having displacement of 0.026 inch, 0.061 inch, and 0.072 inch, respectively. It can be concluded that line meshing method is preferable followed by quadrilateral and finally triangular meshing for this particular simulation. 
Figure 17 shows the difference in meshing size for triangle meshing while figure 18 shows the difference in quadrilateral meshing sizes. Overall changing meshing size results in a small change in results, the finer the meshing, the more precise the result is but more time and computing power is needed. Table 2 shows the difference in displacement and as it can be observed the displacement difference was around 0.0015 inch for the triangular meshing and 0.0032 inch for the quadrilateral meshing.

\section{Triangle Meshing}

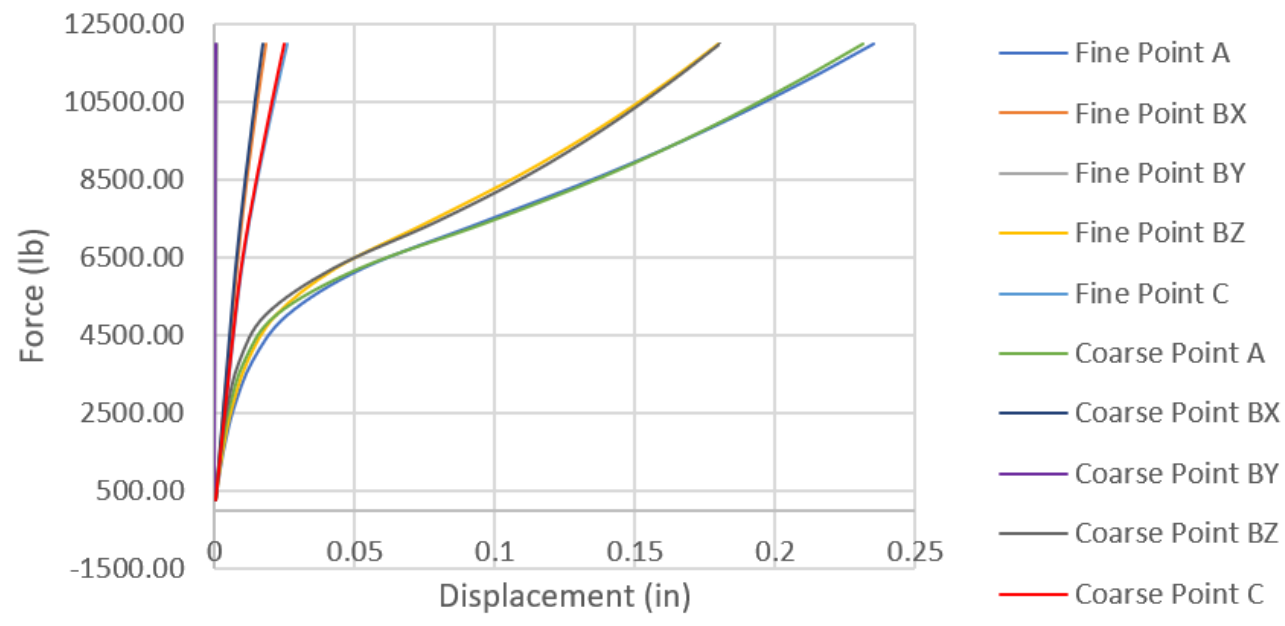

Figure 17 Triangle meshing comparison

Quadrilateral showed slightly more stresses than triangular in all direction, with less stress zones near sides of the fuse. Figures 19 and 20 show the stress distribution for triangle meshing in $\mathrm{X}, \mathrm{Y}$ and $\mathrm{Z}$ directions for both fine and coarse meshing. Comparing stress distributions in the $X$ direction shows that finer meshing has more stresses on the sides of the hole stretching to the sides of the fuse, whereas coarser mesh has stresses more in an oval shape surrounding hole leading to less stress zones near sides of the fuse. In the $Y$ direction, the stresses in finer mesh are less than coarse around the sides of the fuse, coarser mesh has stresses stretching vertically to the edges of the fuse. In the $Z$ direction, coarser meshing show fewer stresses around the edges of the fuse and less stresses above and below the hole. The model with fine mesh shows circular stress zones to the edge of the steel plate fuse. 


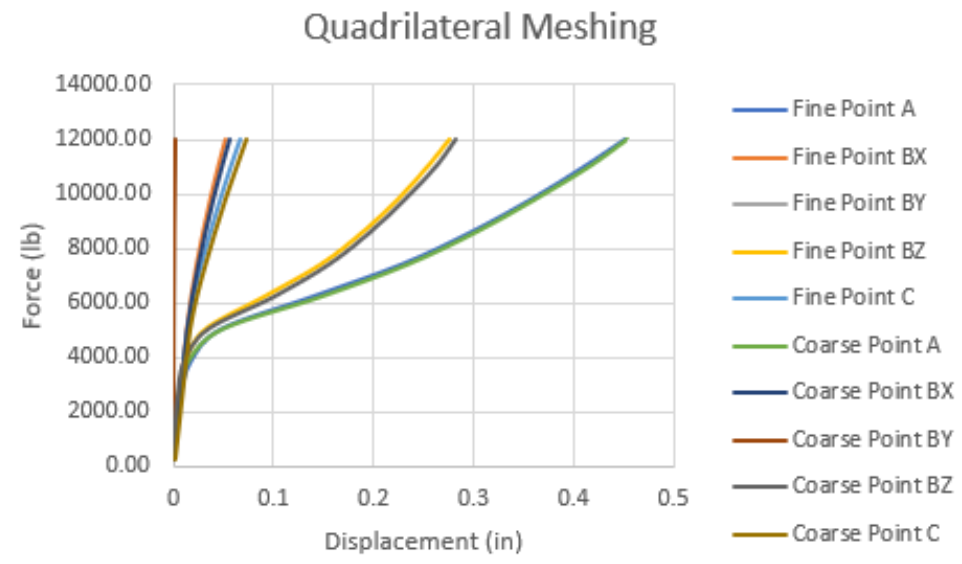

Figure 18 Quadrilateral meshing comparison

\begin{tabular}{|c|c|c|c|c|c|c|}
\hline \multicolumn{7}{|c|}{ Displacement (in) at 12000 lb } \\
\hline \multirow{2}{*}{ Type } & Point A & \multicolumn{3}{c|}{ Point B } & Point C \\
\cline { 3 - 7 } & & UZ & UX & UY & UZ & UX \\
\hline \multirow{2}{*}{ Triangular } & Fine & 0.2353 & 0.0184 & 0.0008 & 0.1797 & 0.0260 \\
& Coarse & 0.2313 & 0.0174 & 0.0004 & 0.1804 & 0.0251 \\
\hline \multirow{2}{*}{ Quadrilateral } & Fine & 0.4516 & 0.0524 & 0.0018 & 0.2754 & 0.0672 \\
& Coarse & 0.4533 & 0.0564 & 0.0016 & 0.2823 & 0.0724 \\
\hline
\end{tabular}

Table 2 Displacement comparison - Meshing

For the quadrilateral meshing (figures 21 and 22), overall there is less difference in stresses between fine and coarse meshing and it is small compared to triangle meshing. In the $\mathrm{X}$ direction, coarse mesh has less stress zones on sides of the fuse whereas fine mesh has more refined stress areas above and below the hole. In the $\mathrm{Y}$ direction, fine mesh has more stresses on sides of the fuse as well as above and below the hole compared to coarse mesh. In the $Z$ direction, coarse mesh shows less stress zones near sides of the hole, whereas fine mesh shows more stresses below the hole. 
A)

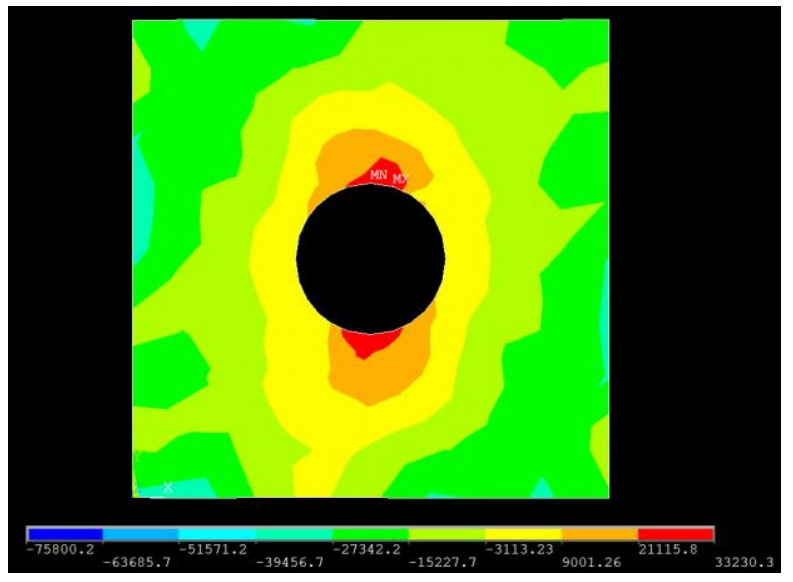

B)

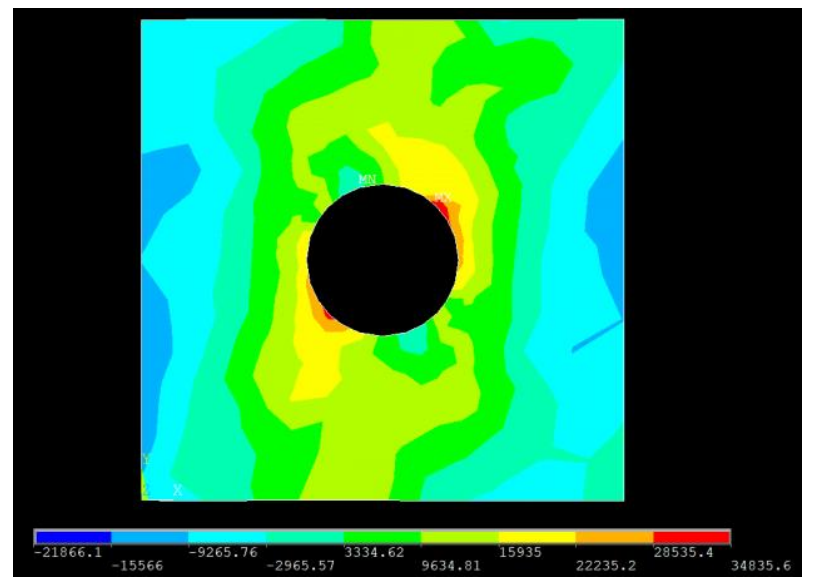

C)

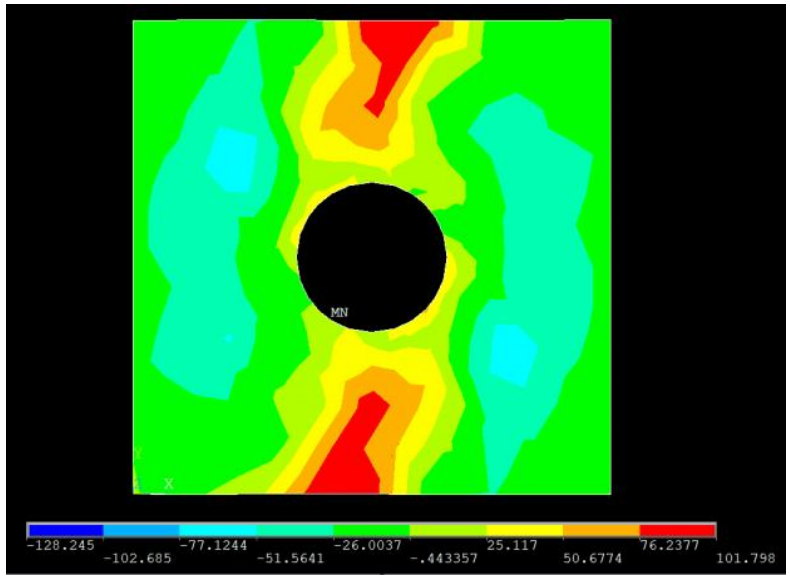

Figure 19 Triangle Fine Meshing - Stress distribution A) X direction B) Y direction C) Z direction

A)

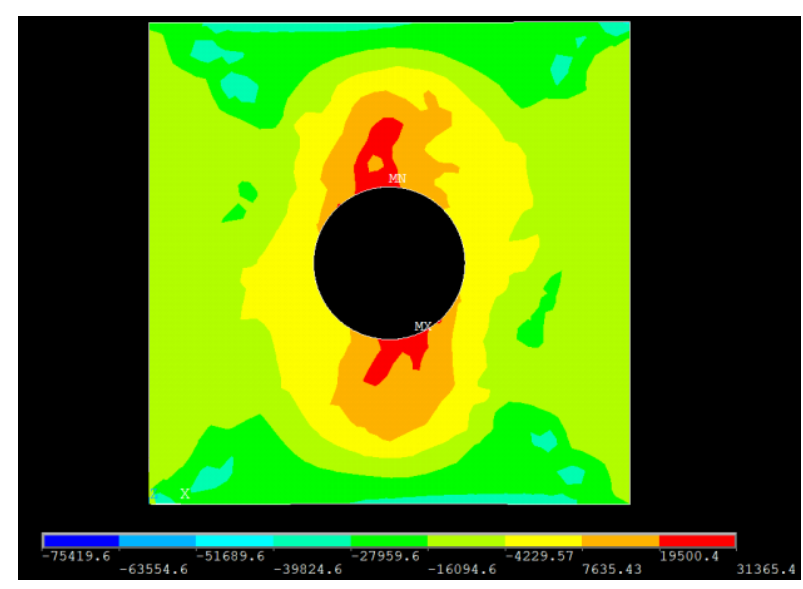

B)

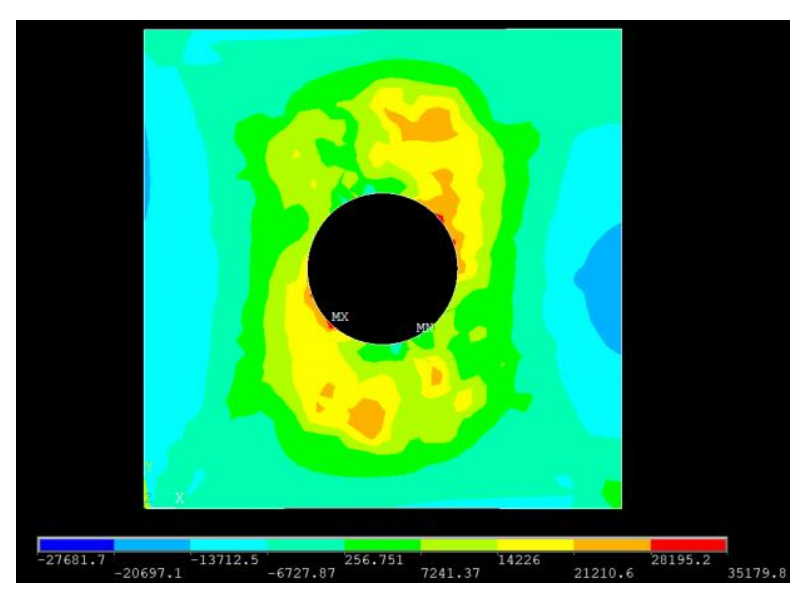

C)

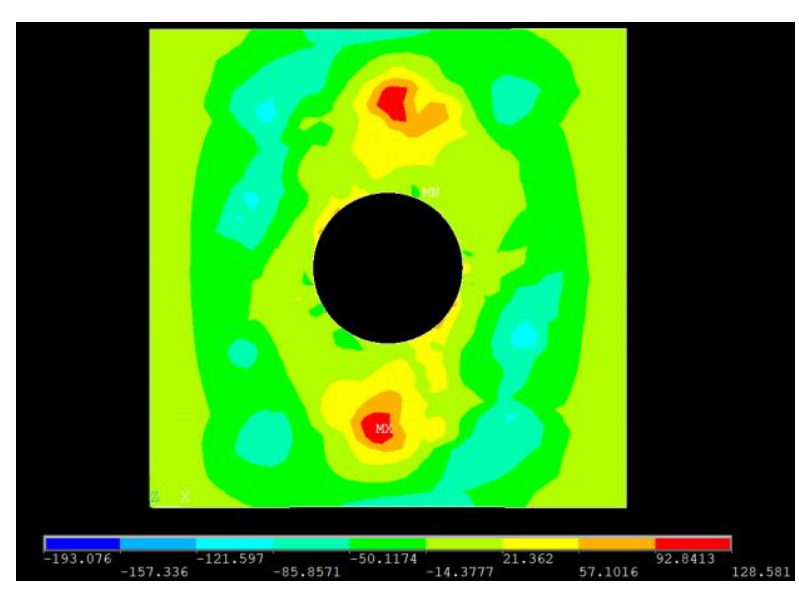

Figure 20 Triangle Coarse Meshing - Stress distribution A) X direction B) Y direction C) Z direction 
A)

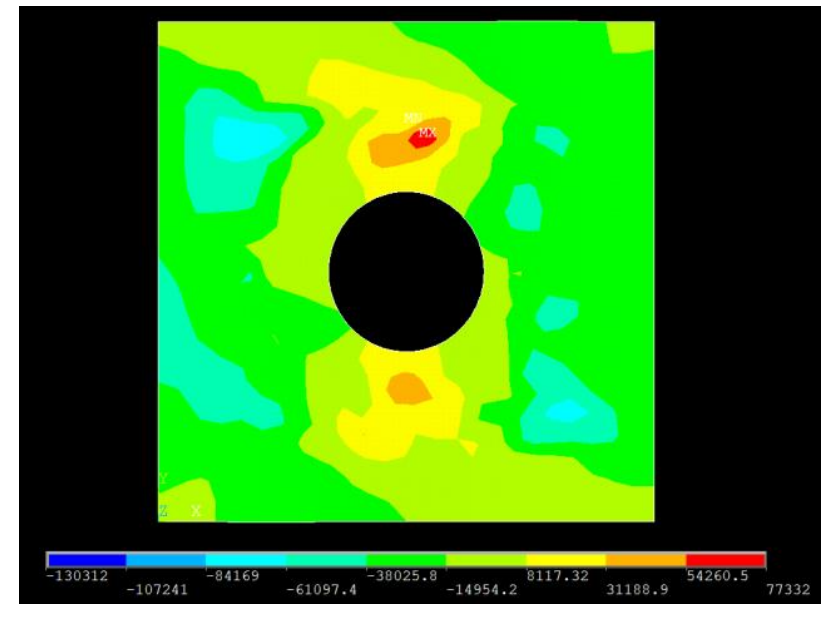

B)

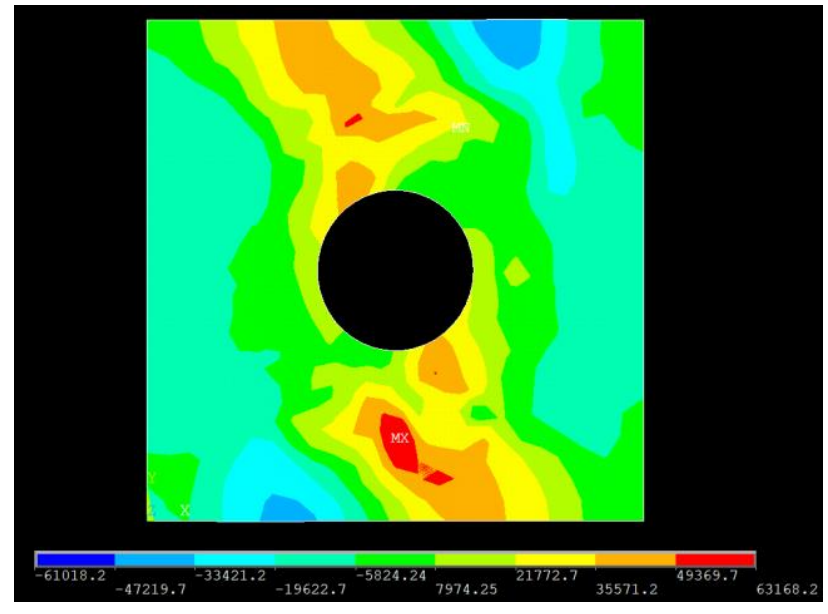

C)

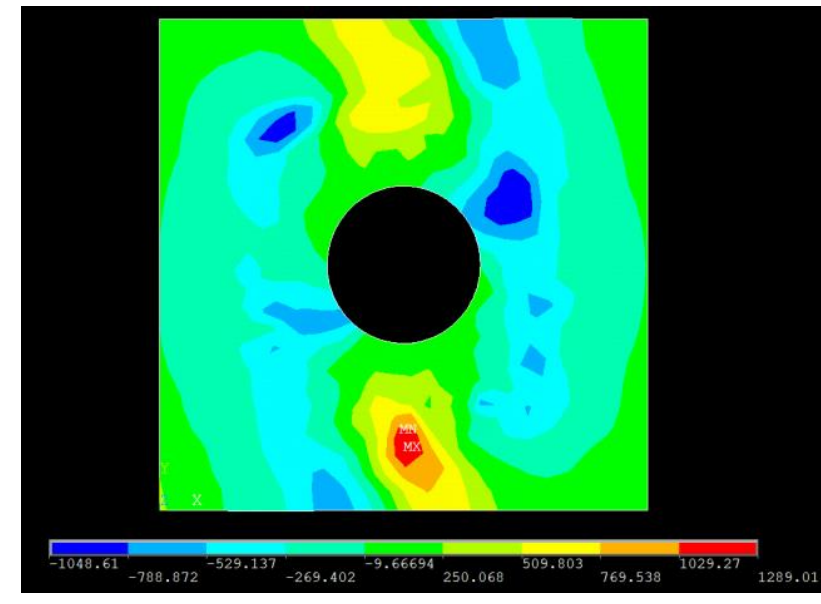

Figure 21 Quadrilateral Fine Meshing - Stress distribution A) X direction B) Y direction C) Z direction

A)

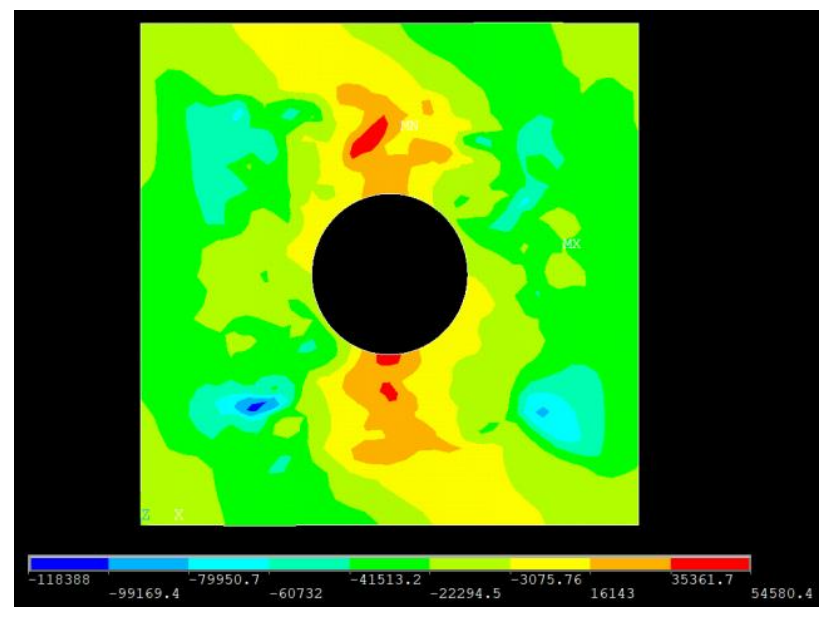

B)

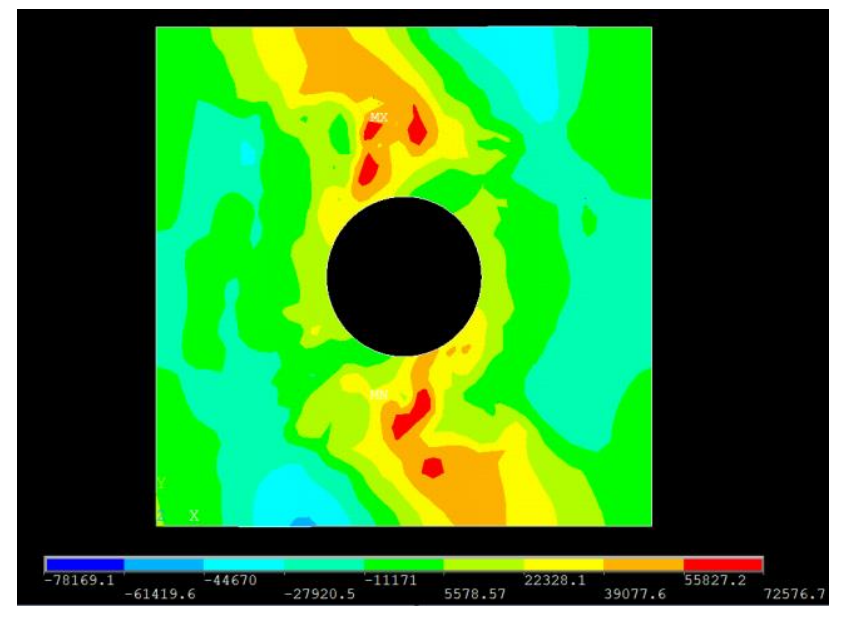

C)

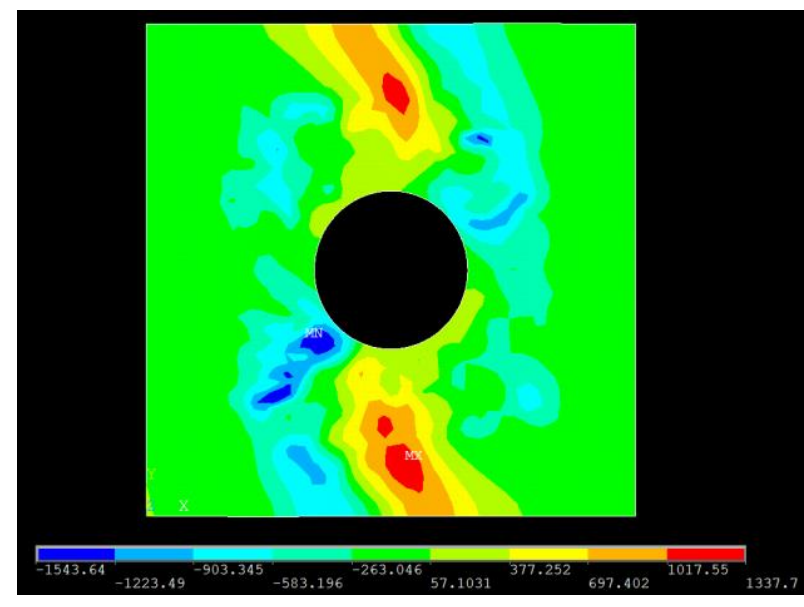

Figure 22 Quadrilateral Coarse Meshing - Stress distribution A) X direction B) Y direction C) Z direction 


\section{Effects of Imperfection Percentage}

The geometrically nonlinear theory presents a good basis for the reliable description of the post buckling behaviour of steel plate fuse. In order to activate the nonlinear response, a sinusoidal imperfection of $1 \%$ of the total plate thickness is initially used and then increased from $1 \%$ to $10 \%$ by modifying equation 1 . Similar to the validation step same points were taken for analysis (i.e. A and B for Z displacement and C for the X Displacement).

$$
\text { For } 1 \% \text { initial imperfection, } z=0.012 \sin \left(\frac{\pi x}{9.5}\right) \sin \left(\frac{\pi y}{9.5}\right) \quad \text { Equation } 1 .
$$

Figure 23 shows the effect of increasing imperfection on point A. As it could be observed, below the force of $8000 \mathrm{lb}$ increasing imperfection increases displacement; though after imperfection 7\% the difference in displacement is just 0.00085 in. As the force increases above $8000 \mathrm{lb}$ the order switches, increasing imperfection percentage decreases displacement. Imperfection at $12000 \mathrm{lb}$ for $1 \%$ is 0.4251 inch while the model with $10 \%$ imperfection showed 0.3887 -inch displacement.

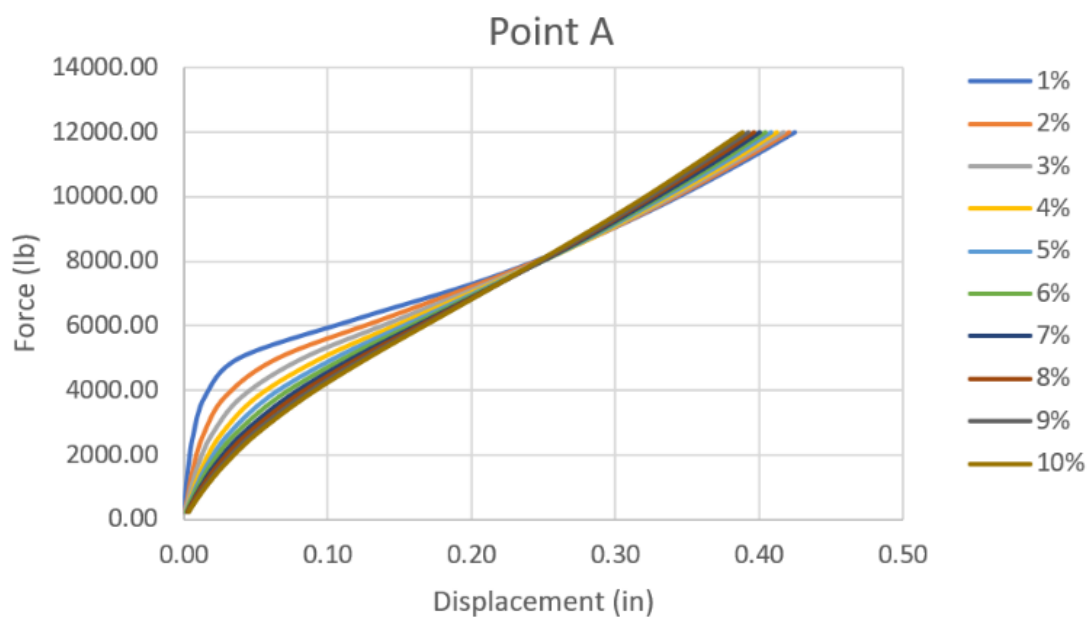

Figure 23 Point A: Z displacement imperfection comparison 


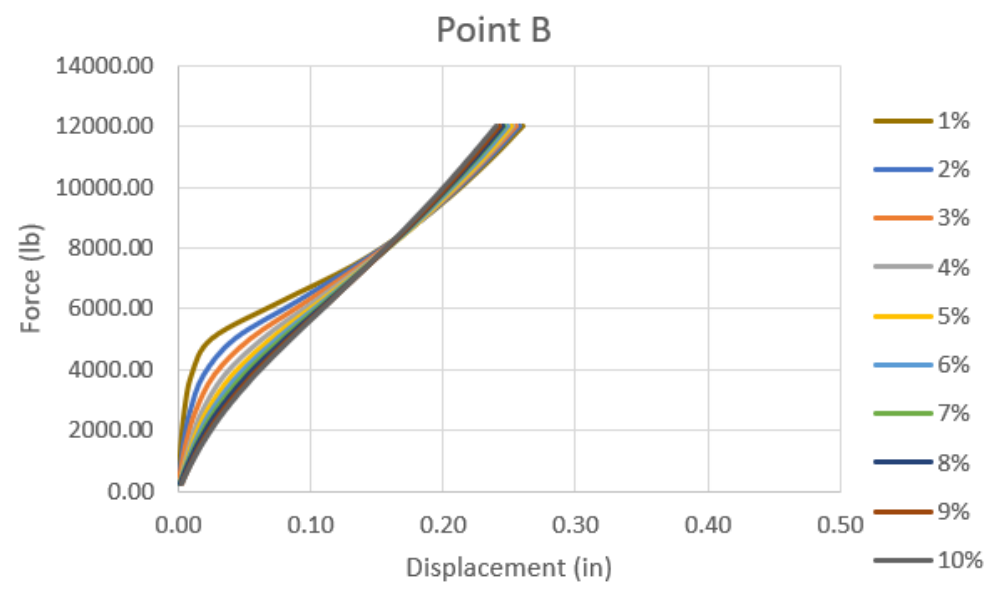

Figure 24 Point B: Z displacement imperfection comparison

Figure 24 shows the effect of increasing imperfection on point B. Similar to point A pattern, point B also increases in displacement as imperfection percentage increases up to load force of $8000 \mathrm{lb}$. Imperfection after $8 \%$ shows little change in displacement. At load $12000 \mathrm{lb}$, the displacement difference of $1 \%$ was 0.259 inch while displacement of $10 \%$ imperfection was 0.240 inch. Point B showed lesser displacement overall than point A. Point B located horizontally from point of loading as shown in figure 9.

Figure 25 shows the effect of increasing imperfection on point $C$ for $X$-axes. Displacement at point $C$ showed lesser variation than that at points A, and B. All imperfection percentages share same initial linear response to increasing force up to $3500 \mathrm{lb}$ after which increasing imperfection percentage increases displacement as force increases. The difference in displacement at maximum force $12000 \mathrm{lb}$ is very small compared to previous points, being 0.061 for $1 \%$ and 0.064 for $10 \%$ imperfection.

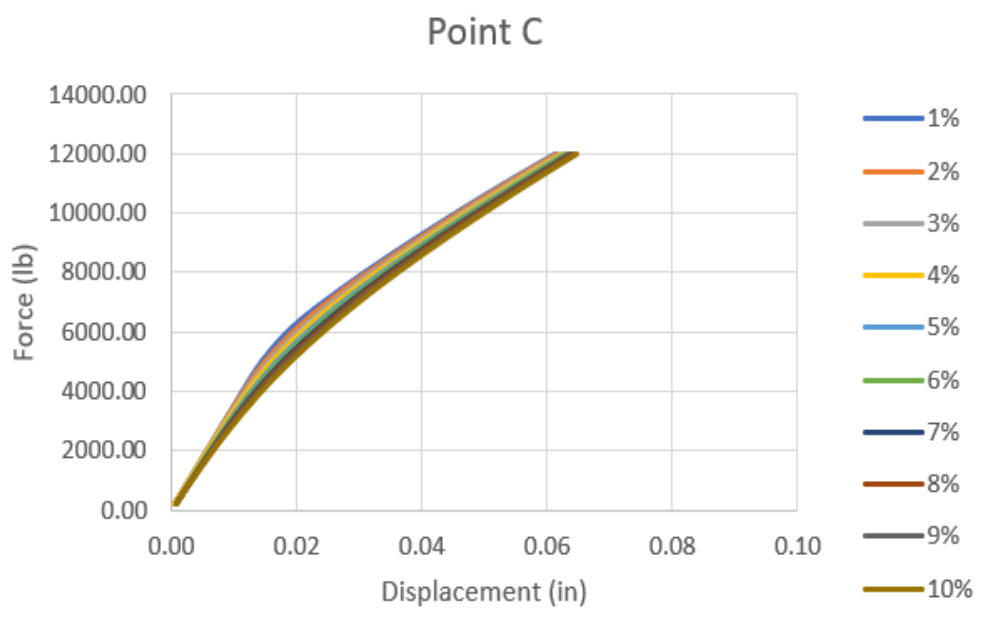

Figure 25 Point C: $X$ displacement imperfection comparison 
Table 3 shows yield strength for each imperfection percentage for all three points. Overall increasing imperfection percentage decreased yield strength, with point A being most effected by increasing imperfection. For point $A$, the difference between $1 \%$ and $3 \%$ is $3000 \mathrm{lb}$, followed by point $B$ with $2700 \mathrm{lb}$, and finally point $C$ with $1900 \mathrm{lb}$. For the $Z$ - axes or in plane points; point $A$ showed steady decrease in yield strength from $4800 \mathrm{lb}$ to $1800 \mathrm{lb}$. Point B showed higher yield strength than point $A$ as it decreased from $5000 \mathrm{lb}$ to $2300 \mathrm{lb}$. Point $\mathrm{C}$ which deals with the $\mathrm{X}$ displacement had the highest yield strength overall and the lowest decrease ratio as it decreased from $5500 \mathrm{lb}$ to $3500 \mathrm{lb}$.

Changing imperfection percentage does not have considerable effect on the stress distribution in all three directions. Figure 26 to figure 28 show the $X, Y$ and $Z$ direction stresses, overall the $Y$ direction faced more stresses than other two, with Z direction being the least stressed. The left and right sides of plate fuse show small stresses while most stresses are concentrated above and below the circular hole. Y direction shows similar behavior but with less stresses on the sides and more stresses above the hole than below. $Z$ direction shows more stresses in the top and bottom portion of the fuse away from the circular hole.

\begin{tabular}{|r|lll|}
\cline { 2 - 4 } \multicolumn{1}{c|}{} & \multicolumn{4}{|c|}{ yield strength (lb) } \\
\hline $1 \%$ & 4800 & 5000 & 5500 \\
$2 \%$ & 4100 & 4600 & 5300 \\
$3 \%$ & 3700 & 4200 & 5000 \\
$4 \%$ & 3300 & 3800 & 4500 \\
$5 \%$ & 2500 & 3500 & 4300 \\
$6 \%$ & 2300 & 3200 & 4000 \\
$7 \%$ & 2100 & 2600 & 3850 \\
$8 \%$ & 2000 & 2500 & 2700 \\
$9 \%$ & 1900 & 2450 & 3650 \\
$10 \%$ & 1800 & 2300 & 3500 \\
\hline
\end{tabular}

Table 3 Yield strength for imperfection comparison 


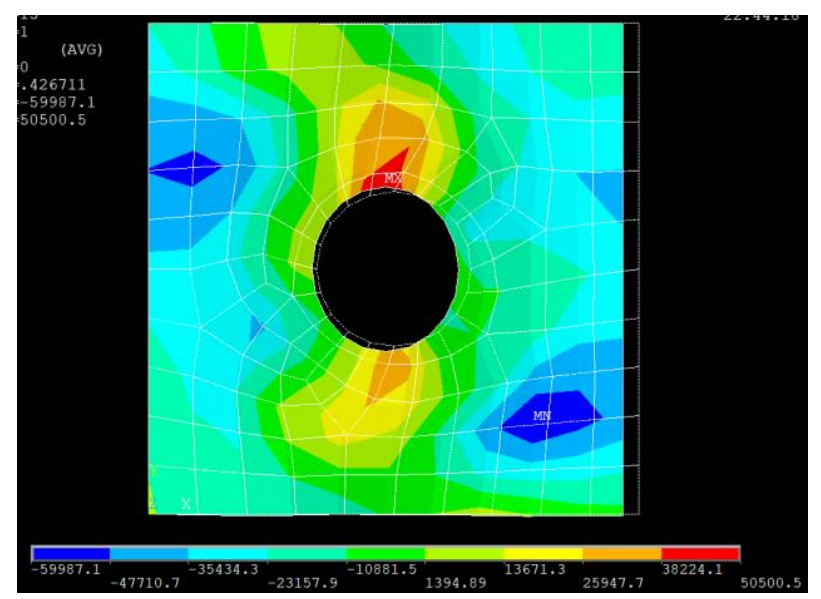

Figure 26 Circular X Direction - Stress distribution (1.5 inch radius)

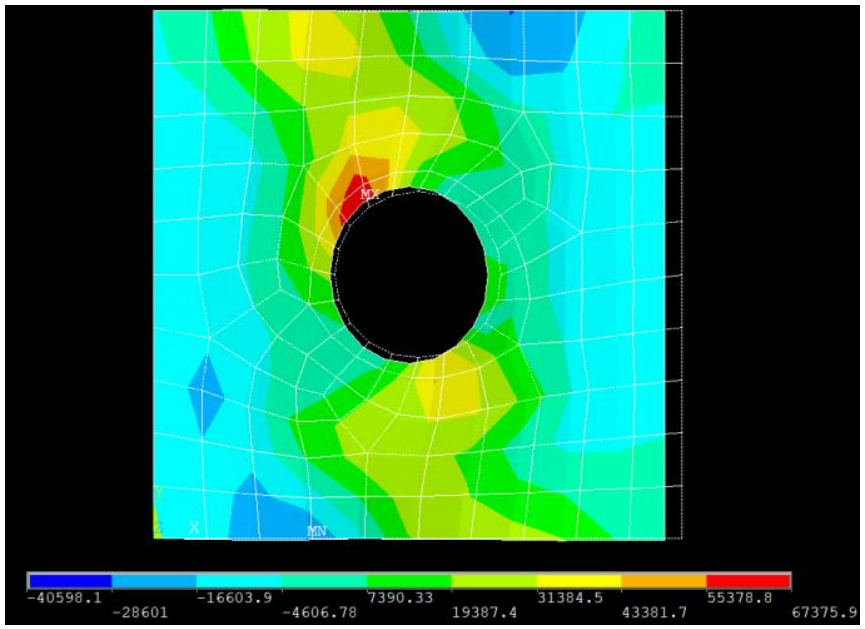

Figure 27 Circular Y Direction - Stress distribution (1.5 inch radius)

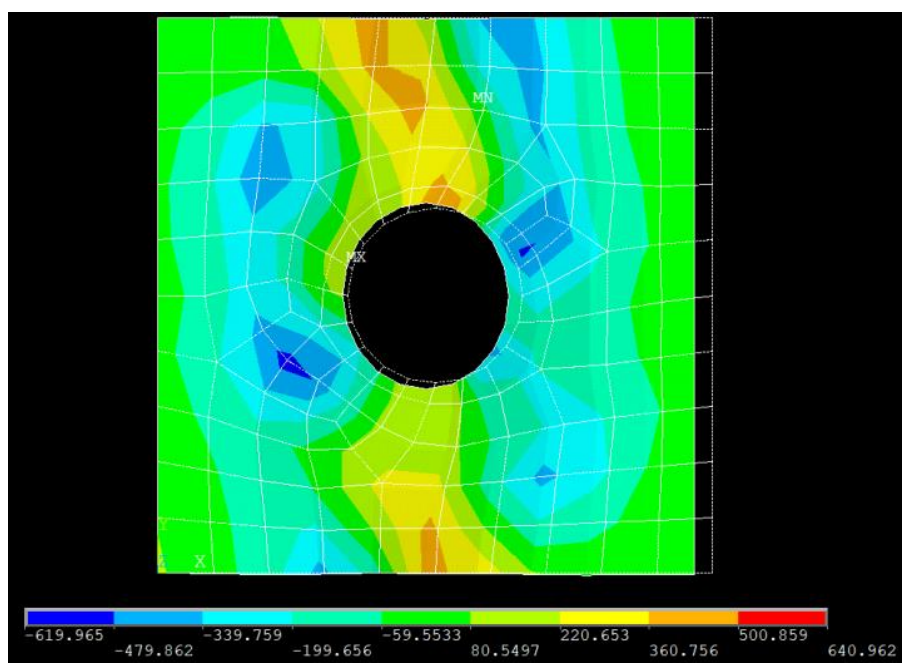

Figure 28 Circular Z Direction - Stress distribution (1.5 inch radius) 


\section{Effects of Hole Shape}

Another input parameter studied is the shape of the hole. Four shapes were analyzed, including circle, diamond, rectangle, and double diamond shape. All other parameters are kept fixed. Figure 29 shows the studied hole shapes and their geometrical details. For this analysis, two points were avergaed A1 and A2 to get consistant results on the $\mathrm{X}$ axes displacment; Point $\mathrm{B}$ is kept similar to previous point $\mathrm{C}$ in the imperfection analysis for comparison.

A)

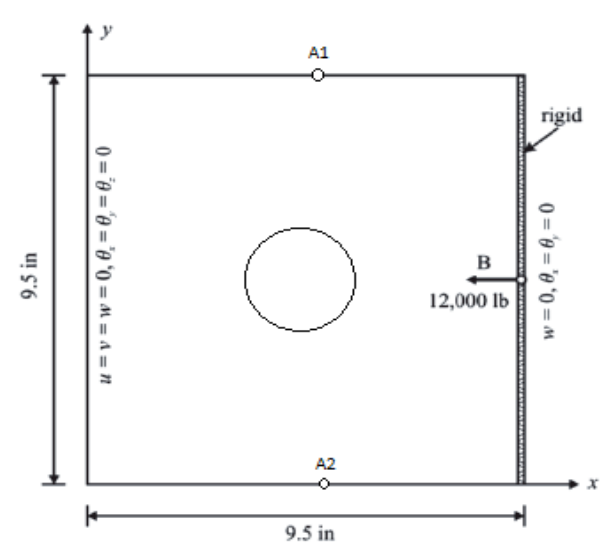

B)

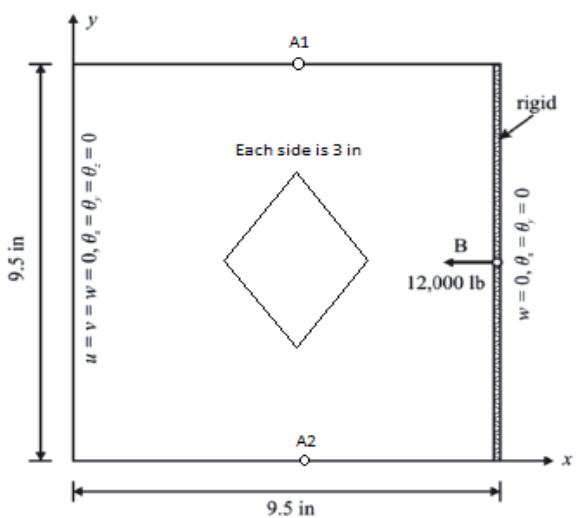

D)

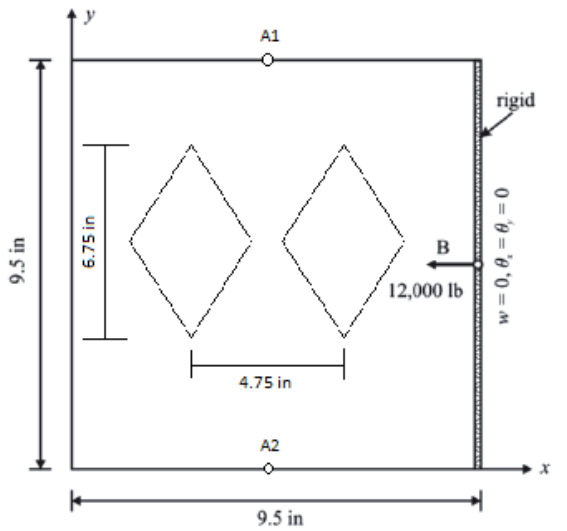

C)

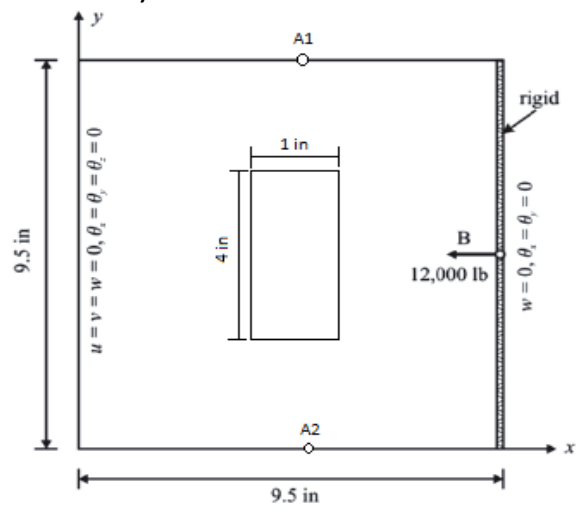

Figure 29 Shape of the hole A) circular (Madenci \& Guven, 2006) B) Diamond C) Rectangular E) Double Diamond

Figure 30 and 31 show the force vs displacement graph with the various shapes. It can be noted that the double diamond shape showed linear elastic behavior, this is also clear in figure 26 showing stresses. The model with a diamond shaped hole showed the least displacement followed by models with circle, rectangle and double diamond shape holes. From figure 30 for point $A$, it is apparent that the model with diamond shape hole had most curvature, reaching displacement of 0.030 inch at $12000 \mathrm{lb}$, and has yield 
strength of $4200 \mathrm{lb}$. The circle shaped hole curvature has a slight deviation from diamond having yield strength of $5300 \mathrm{lb}$ and at $12000 \mathrm{lb}$ with displacement being 0.033 inch. Rectangular hole had yield strength of $3500 \mathrm{lb}$ and displacement of 0.039 inch at $12000 \mathrm{lb}$. Double diamond had displacement of 0.036 inch at $12000 \mathrm{lb}$ slightly lower displacement than the rectanglular hole. Figure 31 for point B shows similar behaviour but with more displacement for each shape. At $12000 \mathrm{lb}$ load, the circle, diamond, rectangle and doble diamond shapes had displacement of $0.061,0.056,0.074$, and 0.079 respectively.

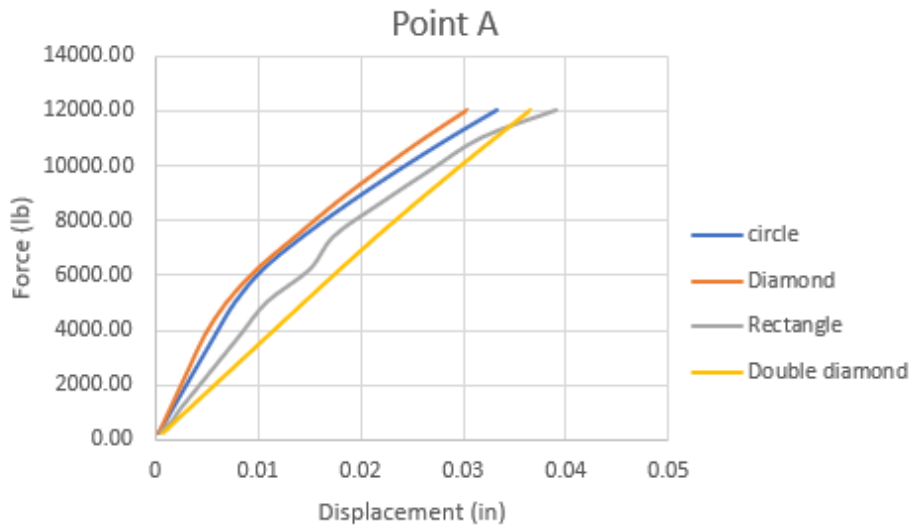

Figure 30 Point A - Changing hole shape

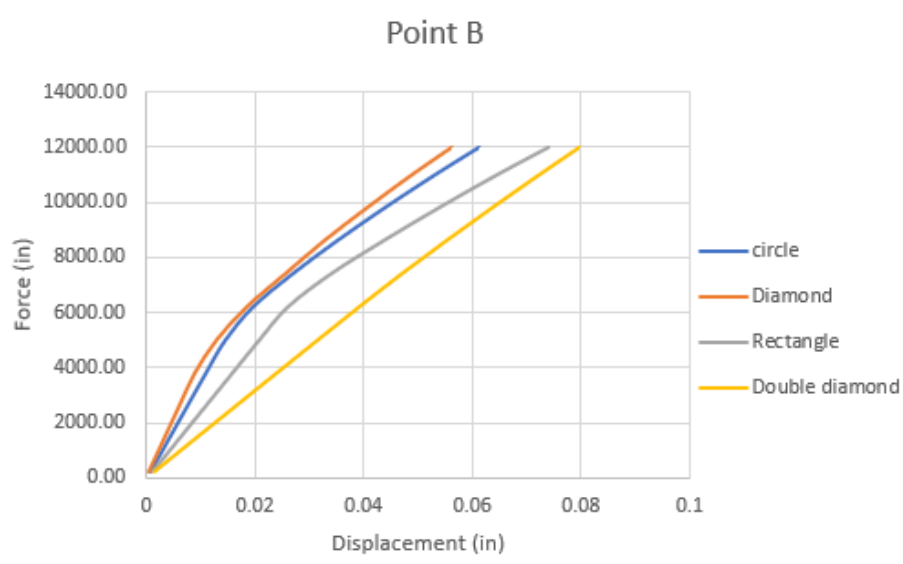

Figure 31 Point B - Changing hole shape

Figures 32 to 34 show the stress distribution for the model with a diamond shaped hole. The diamond shaped hole showed more stresses in the $\mathrm{X}$ direction and least in the $\mathrm{Z}$ or in plane direction. Compared to the circular hole fuse, in the diamond hole fuse, stresses in the $X$ direction seemed to be concentrated in the middle with more stresses on the sides. While the circular shape has less stresses on the right side of 
the fuse, the diamond shaped hole had less stresses on the left side of the fuse. In the $\mathrm{Y}$ direction, the diamond shaped hole showed less stresses overall than the circular. The stresses are focused above and below the diamond hole with more stress being immediately below bottom edge of the diamond. The $Z$ direction stresses are focused below the diamond hole and it stretches to all sides of the fuse, where as in the circular hole fuse the stresses are centred above and below the hole with less stresses on the sides. The $Z$ direction stresses for diamond hole are also less than those for the circular.

Figures 35 to 37 show the double diamond shaped hole stresses. While diamond shaped hole has stresses in $\mathrm{X}$ direction mainly above and below the hole, the double diamond has majority of the stresses on the links or area between the two holes leaving the area above and below holes with uniform displacement. The $Y$ direction have less stresses in the right and left sides of the fuse but have a slightly more stress overall than that in $\mathrm{X}$ direction. The $\mathrm{Z}$ direction has the least stresses overall with similar stress zones to the $X$ and $Y$ directions.

Figure 38 to 40 shows stresses for rectangular shaped hole. For the $X$ and $Y$ direction, the stress zones are similar to previous shapes, with majority of stresses concentrated above and below the hole with the $\mathrm{X}$ direction having more stresses on the right side than $Y$ direction. The $Z$ direction have uniform stress zones throughout the fuse with less stresses concentrated on the edges of the rectangular hole.

Between all shapes, the double diamond hole had the least stresses overall in all directions. For the $\mathrm{X}$ direction, diamond shaped hole had the most followed by circular, rectangular and finally double diamond shaped hole. For the $\mathrm{Y}$ direction, circular had the most stresses followed by rectangular, diamond, and double diamond. For the $Z$ direction, rectangular shaped hole had the most followed by circular, diamond and double diamond shape. 


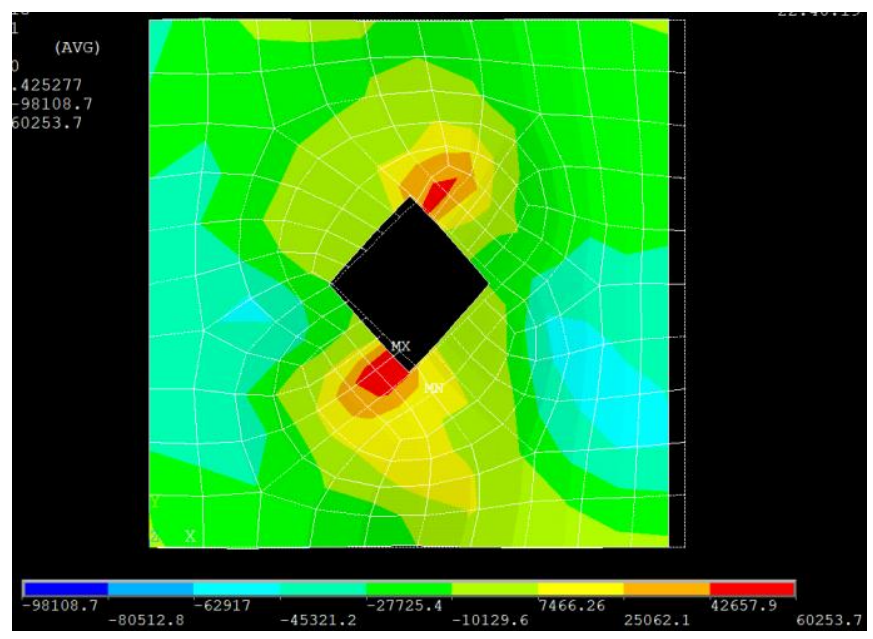

Figure 32 Diamond X Direction - Stress distribution

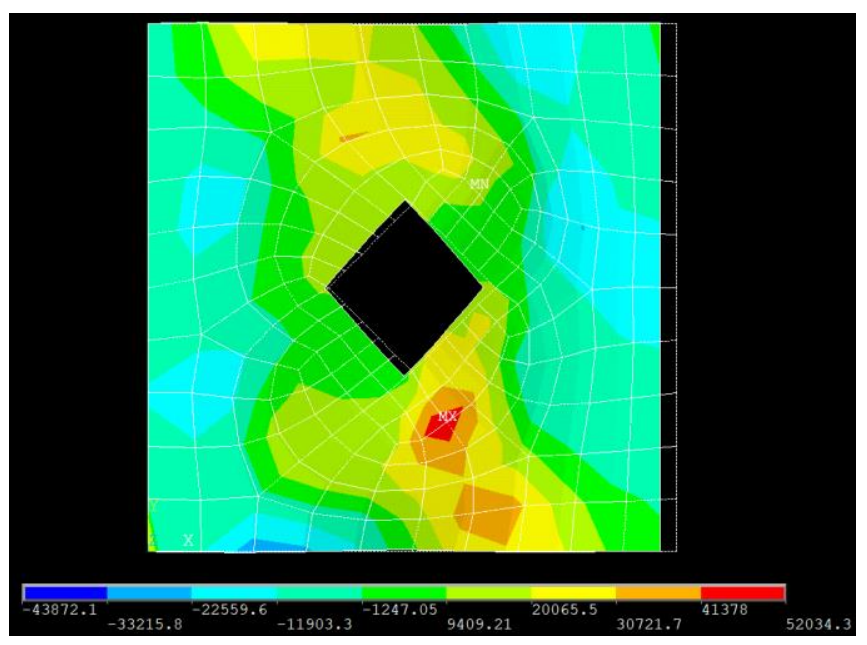

Figure 33 Diamond Y Direction - Stress distribution

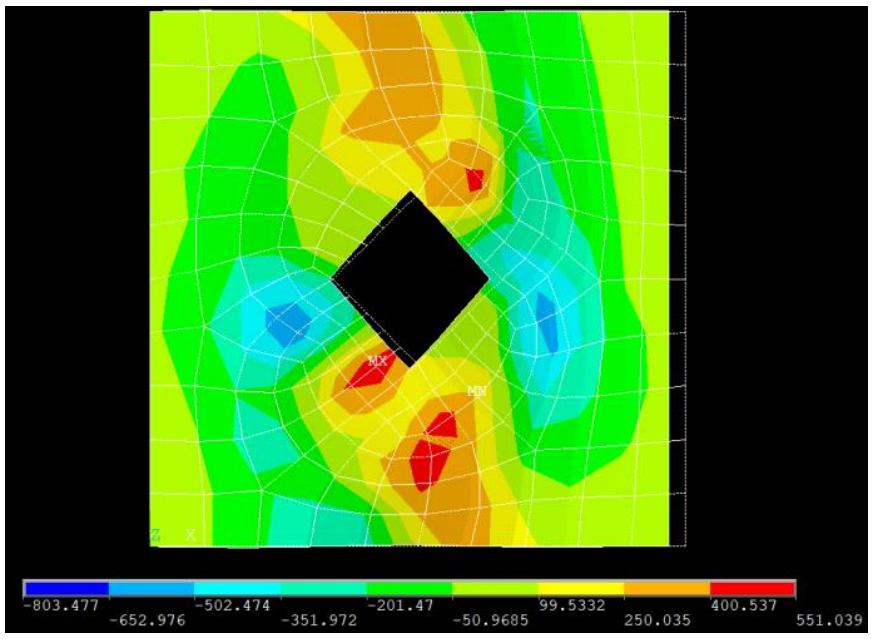

Figure 34 Diamond Z Direction - Stress distribution 


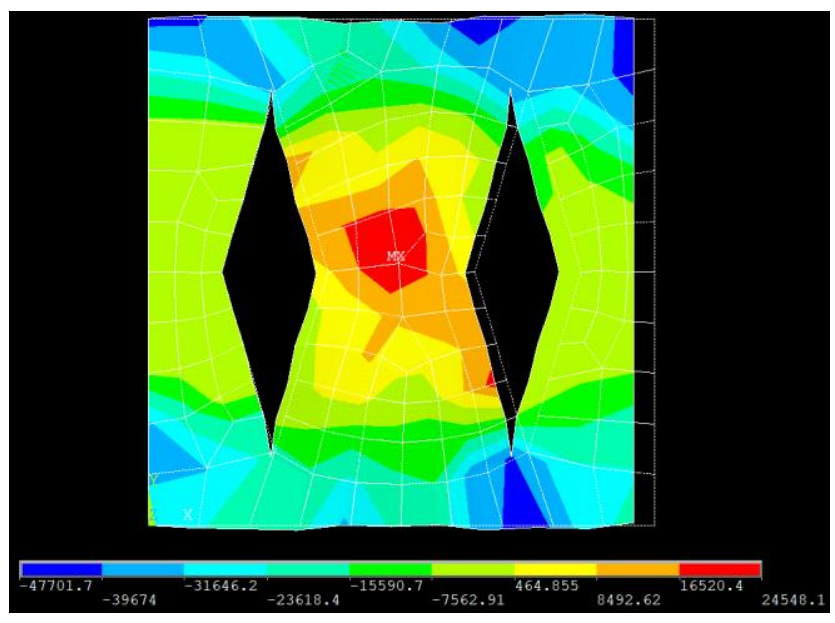

Figure 35 Double Diamond X Direction - Stress distribution

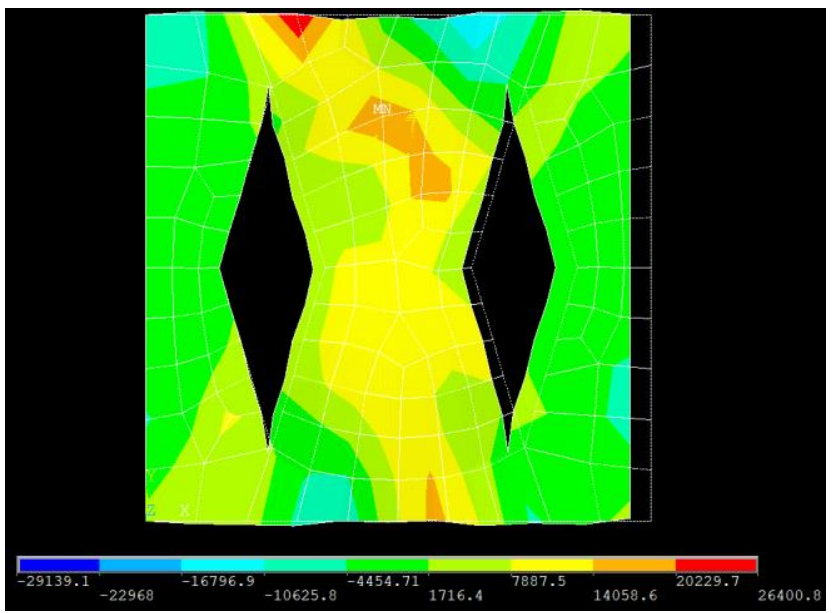

Figure 36 Double Diamond Y Direction - Stress distribution

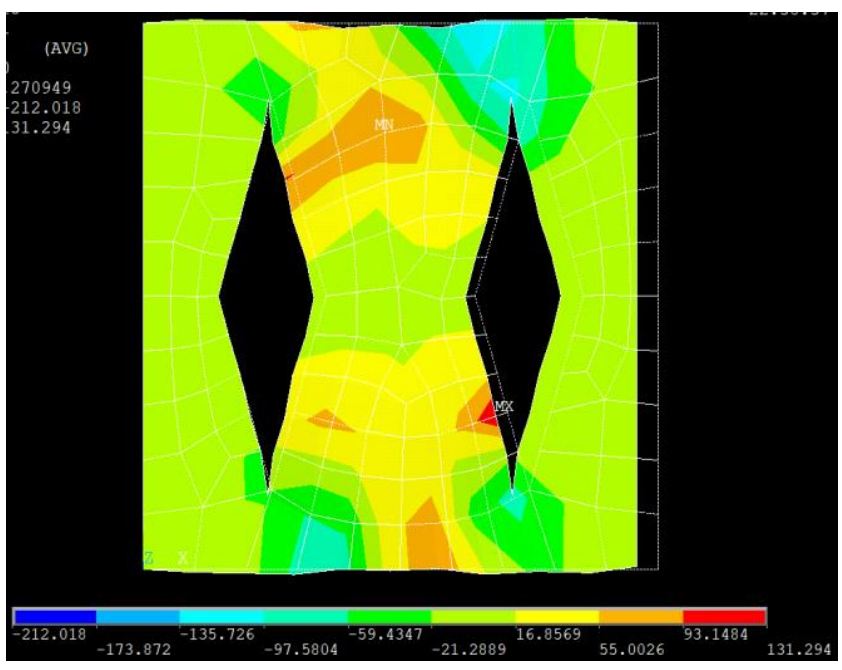

Figure 37 Double Diamond Z Direction - Stress distribution 


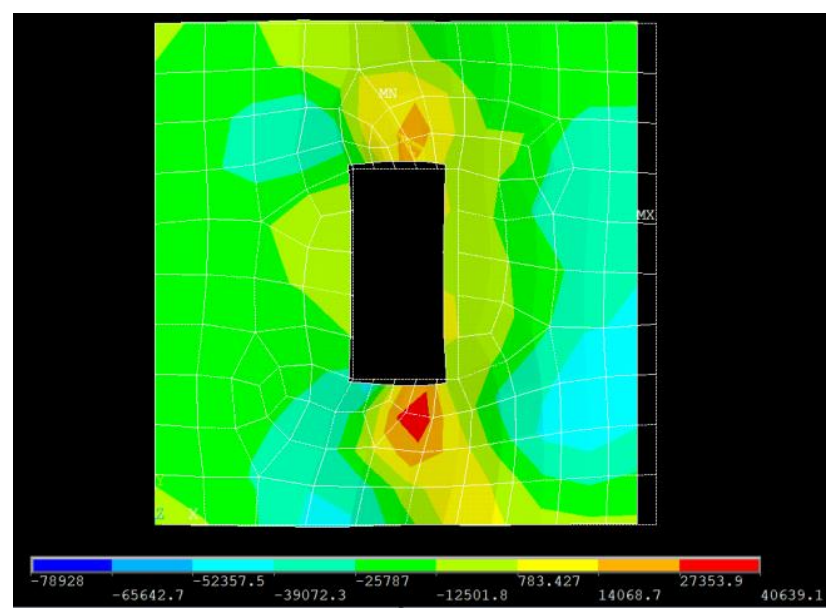

Figure 38 Rectangle shape X Direction - Stress distribution

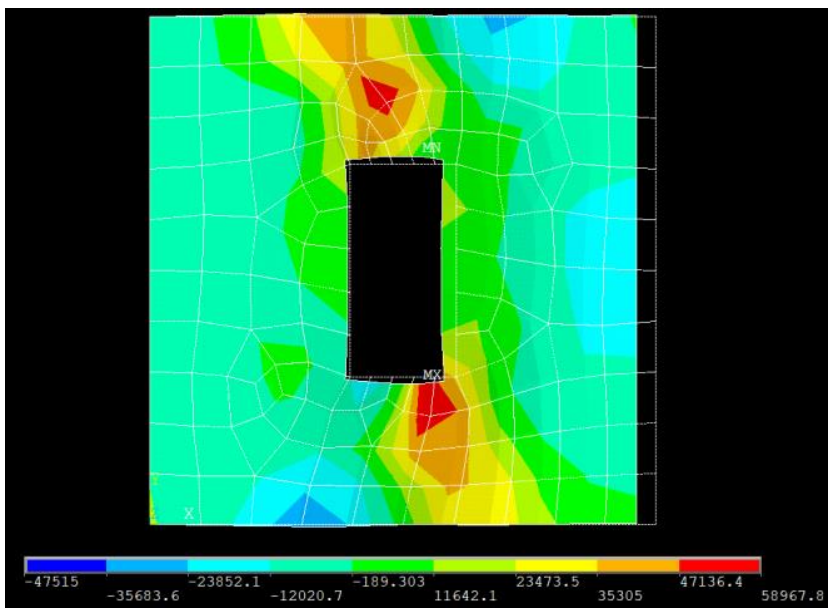

Figure 39 Rectangle shape Y Direction - Stress distribution

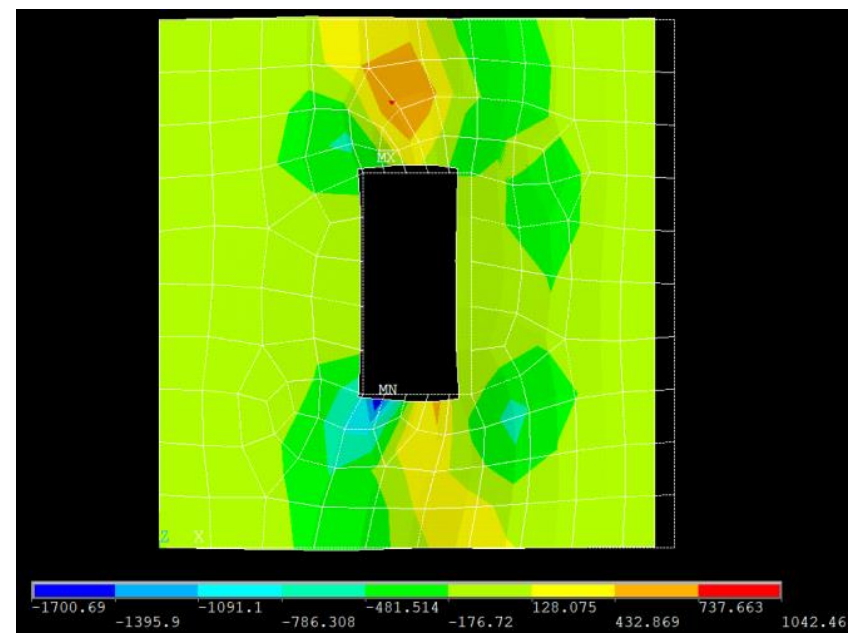

Figure 40 Rectangle shape Z Direction - Stress distribution 


\section{Effects of Hole Size}

To analyze the effects of changing hole size in the steel plate, the fuse with the circular shaped hole will be studied. Four radius values considered are $0.5,1,1.5,2$ and 2.5 inches. Similar to the procedure in the previous sections with layout of figure $29-\mathrm{A}$, points $\mathrm{A} 1$ and $\mathrm{A} 2$ will be averaged for the analysis.

For yield strength analysis, increasing the diameter resulted in an increase in yield strength. Even though the yield strength increases, the initial stiffness (slope of the linear section of the Force/Displacement curve) decreases. Figure 41 shows the response based on the average values at point A. As expected, increasing the hole diameter increases displacement because of the decreased stiffness. The 0.5 and 1 inch radius hole fuses showed very close results and overlap in their initial elastic stages, with displacements at $12000 \mathrm{lb}$ being 0.021 and 0.024 inches, respectively. The 2.5 inch radius followed the 2 inches initially until $6000 \mathrm{lb}$ after which it follows the 1.5 inch path resulting in a displacement of 0.035 inch at $12000 \mathrm{lb}$ force; less than the 2 inch radius which resulted in displacement of 0.04 inches.

Figure 42 for average point B behavior, point B shows a slightly different pattern with overall increased displacement; fuses with radius values of $0.5,1,1.5,2$, and 2.5 inches at $12000 \mathrm{lb}$ showed displacements of $0.045,0.053,0.061,0.076$, and 0.070 inches, respectively.

\section{Point A}

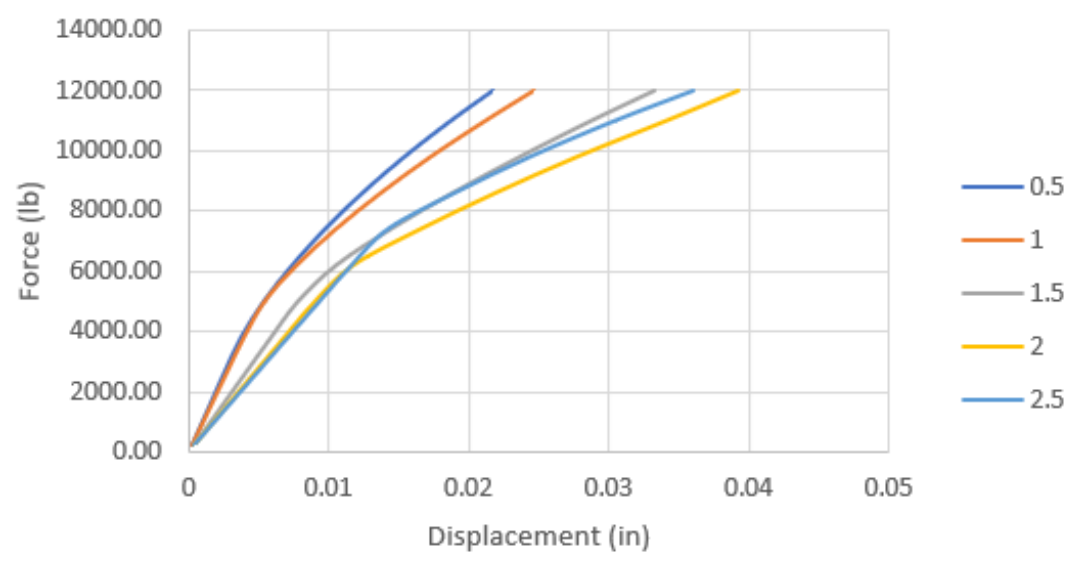

Figure 41 Point $A$ - Changing size of the hole 


\section{Point B}

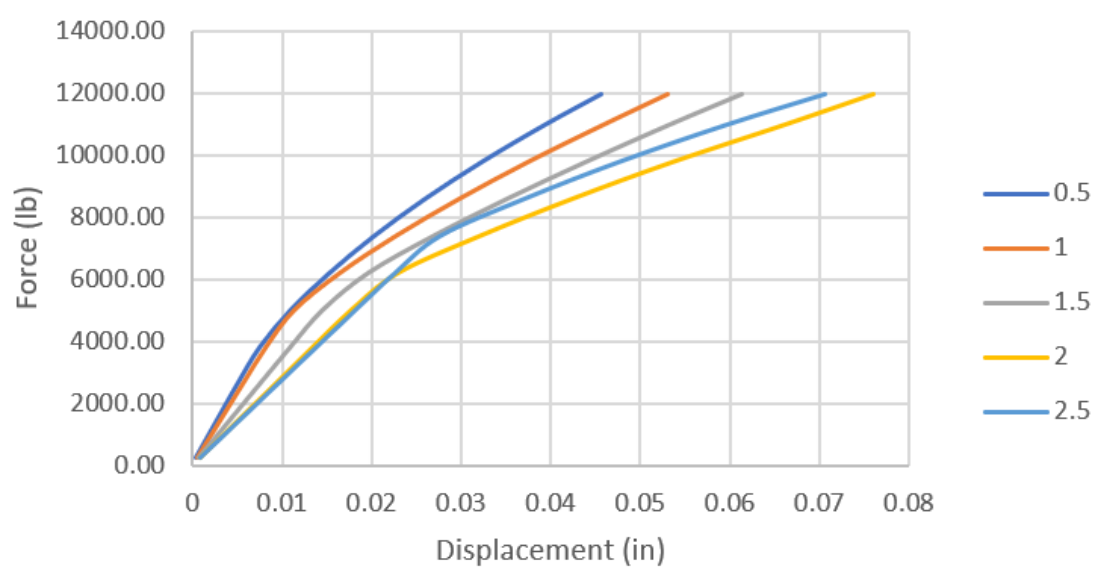

Figure 42 Point B - Changing size of the hole

Figures 43 to 45 show the stresses distribution for 0.5 inch radius, while figures 46 to 48 show stresses for 2.5 inch radius circular hole fuse. As expected, reducing the size of the hole reduces the stress on the fuse. When comparing the $\mathrm{X}$ direction stresses, the 0.5 inch radius showed more stresses all around the hole while the 1.5 and 2.5 inch radius showed concentration of stresses above and below the hole relieving stress from the sides. The fuses with 1.5 and 2.5 inch radius holes show close stress behavior resemblance, with the 2.5 inch case showing slightly less stress on the left side of the fuse. The $Y$ direction stresses share similar behavior to the $\mathrm{X}$ direction except that the 1.5 inch radius have the most stress, followed by 2.5 inch then the 0.5 inch. The $Z$ direction stresses show that increasing radius increases the stress around the hole and reduce the stress on the sides of the fuse. 


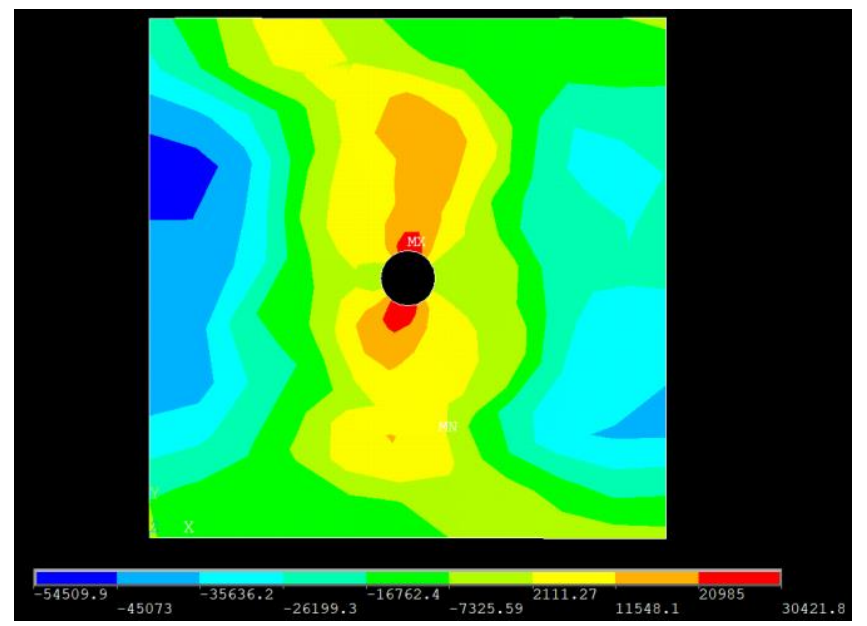

Figure 43 X Direction - Stress distribution - 0.5 inch radius

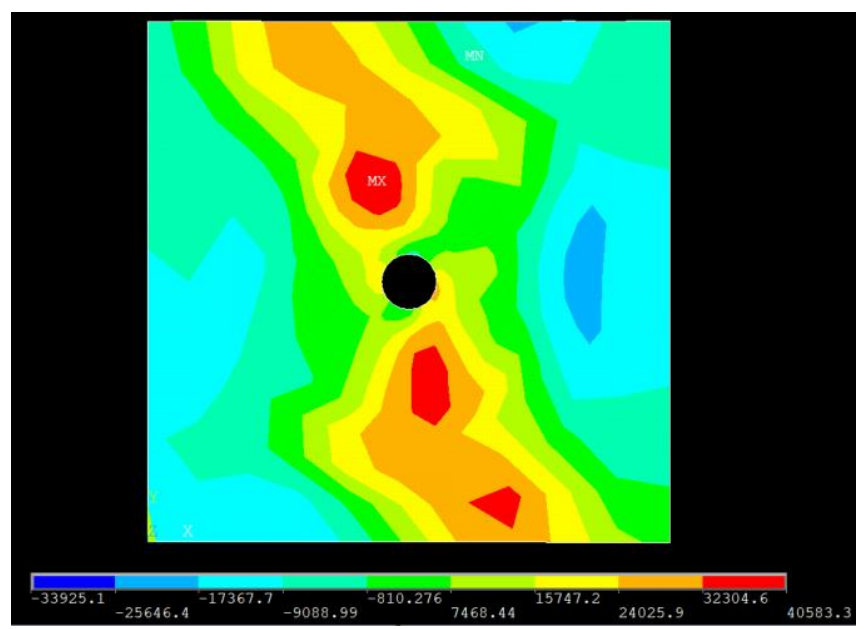

Figure 44 Y Direction - Stress distribution - 0.5 inch radius

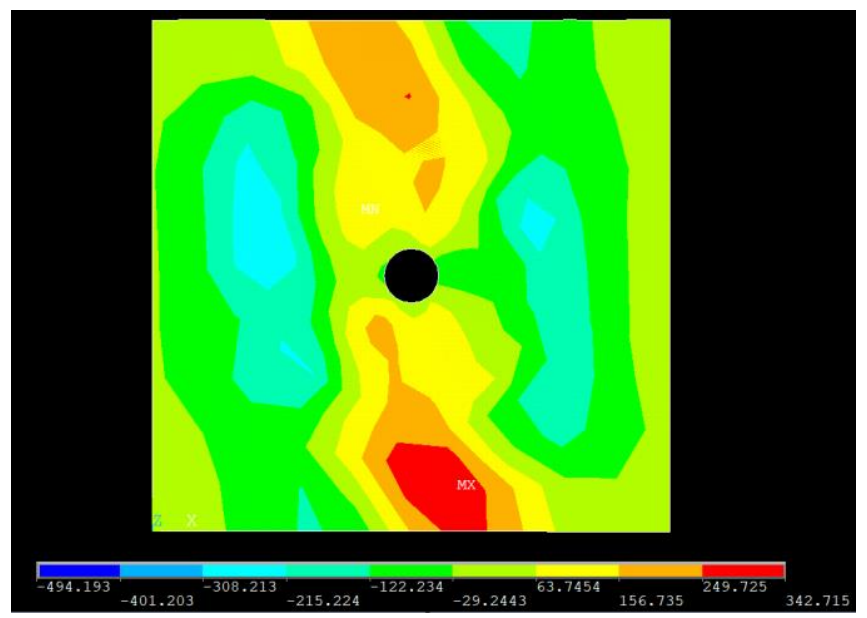

Figure 45 Z Direction - Stress distribution - 0.5 inch radius 


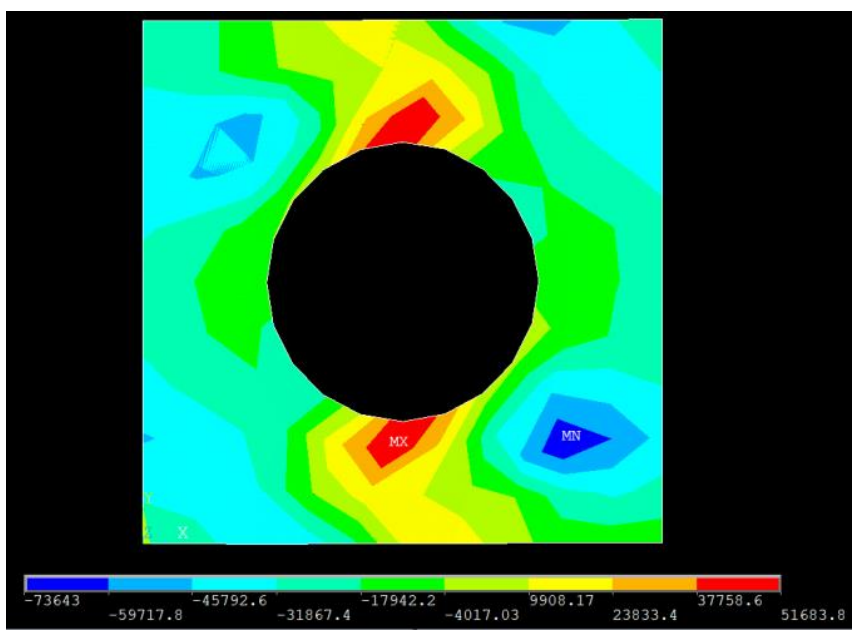

Figure 46 X Direction - Stress distribution - 2.5 inch radius

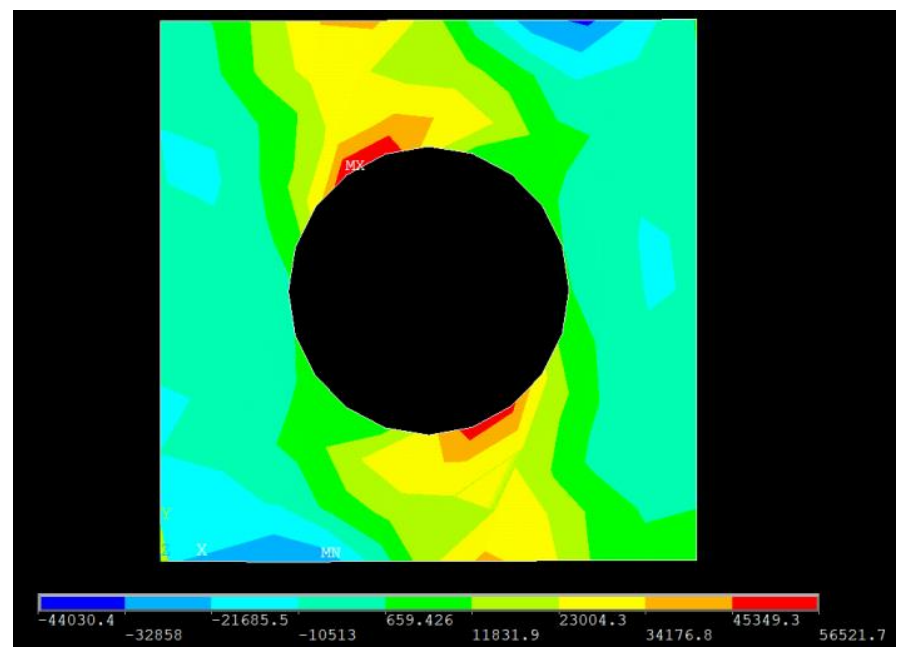

Figure 47 Y Direction - Stress distribution - 2.5 inch radius

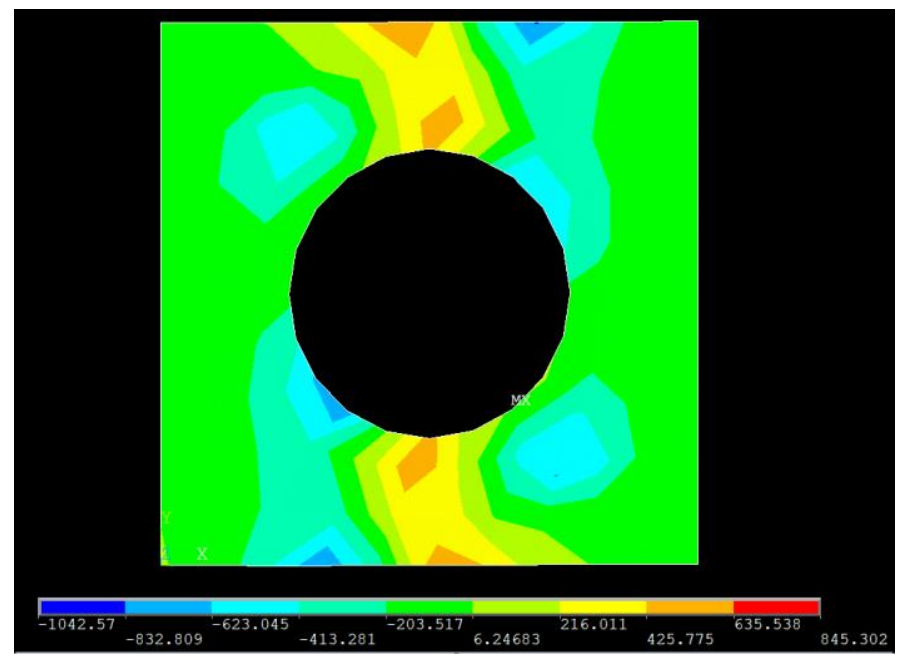

Figure $48 \mathrm{Z}$ Direction - Stress distribution - 2.5 inch radius 


\section{Conclusion}

Steel plate fuses are passive energy dissipation devices that are used to enhance structural performance by reducing seismically induced structural damage. Steel plate fuses dissipate energy through inelastic deformation, they are designed in a way that allow all damage to be concentrated on the fuse allowing the primary structure to remain elastic. After an earthquake, the downtime and the need for repair are minimized as only the fuse would need to be repaired.

After validating the finite element model, several input variables were changed and their affects on stress distribution, displacement, yield strength and deformation were studied.

For imperfection, it was concluded that increasing imperfection increases displacement. In terms of yield strength, increasing imperfection decreases yield strength. In terms of stress distribution, changing the imperfection showed a slight reduction in stresses overall.

Changing the shape of the hole showed that the plate with a rectangular hole had the most displacement followed by the fuses with double diamond, circular and diamond shaped hole. Comparing the stress distribution showed that the double diamond hole had the least stresses in all directions. While other shapes have more stresses above and below the hole, the double diamond had majority of the stresses concentrated on the link or the area between the two holes. The analysis showed that increasing the diameter of the circular hole resulted in an increase in the yield strength. It was also concluded that increasing the hole diameter increased the displacement and the stress in the plate.

Finally, it was observed that the finer the meshing the more precise the simulation is, but the analysis took more time. Generally, structural elements without mid nodes produce more accurate results in quadrilateral meshing than triangular. Quadrilateral meshing method showed more displacement than triangular meshing, with fine meshing having less displacement in $\mathrm{X}$ and $\mathrm{Y}$ directions. For stress distribution, the model with quadrilateral meshing showed more uniform stress distribution, with slight increase in stresses near the hole than triangle meshing. 


\section{References}

ANSYS. (2019). ANSYS ${ }^{\circledR}$ ANSYS Mechanical APDL, Release 18.1.

Bayat, M., \& Abdollahzadeh, G. (2011). On the Effect of The Near Field Records on The Steel Braced Frames Equipped With Energy Dissipating Devices. Solid Structures, 8(4).

Chan, R., \& Albermani, F. (2008). Experimental Study of Steel Slit Damper for Passive Energy Dissipation. Engineering Structures, 30, 1058-1066.

Chen, S., \& Jhang, C. (2011). Experimental Study of Low-Yield-Point Steel Plate Shear Wall Under InPlane Load. J Construction Steel Research, 67, 977-985.

Deierlein, G., Ma, X., Eatherton, M., Krawinkler, H., Billington, S., \& Hajjar, J. (2008). Controlled Rocking of Steel-Framed Buildings with Replaceable Energy-Dissipating Fuses. . WCEE, 8.

Deng, K., Pan, P., Sun, J., Liu, J., \& Xue, Y. (2014). Shape Optimization Desgin of Steel Shear Panel Dampers. J Constr Steel Res, 187-93.

ElBahey, S., \& Bruneau, M. (2011, 2). Bridge Piers with Structural Fuses and Bi-Steel Columns: Experimental testing. ASCE, 11.

Foti, D., Nobile, R., \& Diaferio, M. (2013). Dynamic Behavior of New Aluminum - Steel Energy Dissipating Devices. Structural Control and Health Monitoring, 20, 1106-1119.

Ghabraie, K., Chan, R., Huang, X., \& Xie, Y. (2010). Shape Optimization of Metallic Yielding Devices for Passive Mitigation of Seismic Energy. Engineering Structures, 32, 2258-3367.

Kobori, T., Miura , Y., Fukuzawa, E., Yamada T., Arita , T., Takenaka, Y., . . Tanaka , N. (1992). Development and Application of Hysteresis Steel Dampers. Proc World Conference on Eathquake Engineering, 4(10), 2341-2346.

Kurokawa, Y., Sakamoto, M., Yamada, T., Kurino, H., \& Kunisue, A. (1998). Seismic Desgin of A Tall Building With Energy Dissipation Damper for Attenuation of Torsional Vibration. Structural Desgin of Tall Buildings, 7, 21-32.

Lee, C., Ju, Y., Min, J., Lho , S., \& Kim, S. (2015). Non-Uniform Steel Strip Dampers Subjected to Cyclic Loadings. Engineering Structures(99), 192-204.

Ma, X., Krawinkler, H., \& Deierlein, G. (2011). Semic Design and Behavior of Self Centering Braced Frame with Controlled Rocking and Energy Dissipating Fuses. Stanford University. Stanford: John A. Blume Earthquake Engineering center.

Madenci, E., \& Guven, I. (2006). The Finite Element Method and Application in Engineering Using ANSYS. Springer.

Perri, F., Faella, C., \& Martinelli, E. (2016). Cost-Competitive Hysteretic Devices for Seismic Energy Dissipation in Steel Bracings: Experimental Tests and Low-Cycle Fatigue Characterisation. Construction and Building Material, 113, 57-67. 
Shin, D., \& Kim, H. (2018). Low-Cycle Fatigue Failure Prediction of Steel Yield Energy Dissipating Devices Using a Simplifed Method. International Journal of Steel Structures, 18(4), 1384-1396.

Soong, T., \& Spencer, B. (2002). Supplement Energy Dissipation: State of the Art and State of Practice. Engineering Structure, 24(1), 243-259.

Symans MD, C. F. (2008). Energy Dissipation Systems for Seismic Applications: Current Practice and Recent Developments. ASCE J., 134(1), 3-21.

Vargas, R., \& Bruneau, M. (2006, March 16). Analytical Investigation of the Structural Fuse Concept. MCEER, 392.

Xiang, M., Borchers, A., Pena, A., Krawinkler, H., Bellington, S., \& Deierlein, G. (2011, December). Desgin and Behavior of Steel Shear Plates with Openings as Energy Dissipating Fuses. Blume Earthquake Engineering Center. 